NBER WORKING PAPER SERIES

\title{
FINANCIALLY CONSTRAINED STOCK RETURNS
}

\author{
Dmitry Livdan \\ Horacio Sapriza \\ Lu Zhang \\ Working Paper 12555 \\ http://www.nber.org/papers/w12555
NATIONAL BUREAU OF ECONOMIC RESEARCH
1050 Massachusetts Avenue
Cambridge, MA 02138 \\ October 2006
}

We acknowledge helpful suggestions from Joao Gomes, Leonid Kogan, Martin Schneider (AFA discussant), Amir Yaron, and participants at the American Finance Association Annual Meetings for 2005 in Philadelphia. Most of this work was completed while Lu Zhang was on the faculty of University of Rochester's Simon School of Business, whose support is gratefully acknowledged. This paper supersedes our working paper previously circulated under the title "A neoclassical model of financially constrained stock returns." All remaining errors are our own. The views expressed herein are those of the author(s) and do not necessarily reflect the views of the National Bureau of Economic Research.

(C) 2006 by Dmitry Livdan, Horacio Sapriza, and Lu Zhang. All rights reserved. Short sections of text, not to exceed two paragraphs, may be quoted without explicit permission provided that full credit, including $(\mathrm{C}$ notice, is given to the source. 
Financially Constrained Stock Returns

Dmitry Livdan, Horacio Sapriza, and Lu Zhang

NBER Working Paper No. 12555

October 2006

JEL No. G12,G31,G32

\section{ABSTRACT}

More financially constrained firms are riskier and earn higher expected returns than less financially constrained firms, although this effect can be subsumed by size and book-to-market. Further, because the stochastic discount factor makes capital investment more procyclical, financial constraints are more binding in economic booms. These insights arise from two dynamic models. In Model 1, firms face dividend nonnegativity constraints without any access to external funds. In Model 2, firms can retain earnings, raise debt and equity, but face collateral constraints on debt capacity. Despite their diverse structures, the two models share largely similar predictions.

Dmitry Livdan

Mays School of Business

Texas A\&M University

351-J Wehner Hall

College Station, TX 77843-4218

DLivdan@mays.tamu.edu

Horacio Sapriza

Department of Finance and Economics

Rutgers Business School - Newark

and New Brunswick

111 Washington Street

MEC Building, Room 122

Neward NJ 07102

hsapriza@andromeda.rutgers.edu
Lu Zhang

Associate Professor of Finance

Stephen M. Ross School of Business

University of Michigan

701 Tappan Street, ER 7605 Bus Ad

Ann Arbor MI, 48109-1234

and NBER

zhanglu@bus.umich.edu 


\section{Introduction}

Corporate finance and macroeconomics have studied in depth the effects of financial constraints on firm value, capital investment, and business cycles. ${ }^{1}$ A small but growing asset pricing literature asks how these constraints affect risk and expected returns. Using the Kaplan and Zingales (1997) index of financial constraints, Lamont, Polk, and Saá-Requejo (2001) report a puzzling finding that more constrained firms earn lower average returns than less constrained firms. However, using an alternative index estimated from investment Euler equation, Whited and Wu (2006) find that more constrained firms earn higher average returns than less constrained firms, although the difference is insignificant. Finally, Gomes, Yaron, and Zhang (2006) find that financial constraints provide a common factor for the cross section of returns, but somewhat surprisingly, the shadow price of external funds is procyclical, so that financial constraints are more binding in economic booms.

We use neoclassical economics to study the structural relations between financial constraints, stock returns, and economic fluctuations. Conflicting evidence and competing interpretations are difficult to evaluate without models that tie the characteristics in question to risk and expected returns. We try to fill this gap using two dynamic models. In Model 1, firms face dividend nonnegativity constraints without access to external equity or debt. Model 2 is more realistic as firms can retain earnings, raise debt and equity, but face collateral constraints that limit their debt capacity.

Despite their diverse structures, these two models share largely similar predictions. Small firms, less profitable firms, and firms already in debt are more likely to be constrained. More important, more constrained firms are riskier and earn higher expected returns than less constrained firms. However, this effect can largely be subsumed quantitatively by market capitalization and book-tomarket equity. Further, financial constraints are more binding in economic booms, a pattern driven by the stochastic discount factor that makes capital investment more sensitive to aggregate shocks.

\footnotetext{
${ }^{1}$ An incomplete list of this voluminous literature includes Fazzari, Hubbard, and Petersen (1988), Bernanke and Gertler (1989), Whited (1992), Bond and Meghir (1994), Gertler and Gilchrist (1994), Kaplan and Zingales (1997), Kiyotaki and Moore (1997), Bernanke, Gertler, and Gilchrist (1999), Gomes (2001), Hennessy (2004), Moyen (2004), Almeida and Campello (2005), and Henessy and Whited (2006).
} 
Our explicitly-solved models provide rich insights on the precise economic mechanisms driving the model predictions. Intuitively, the shadow price of new funds for a given firm is determined by its financial gap, the difference between its investment demand and internal funds. The higher the gap, the more financially constrained the firm will be. For small firms with small scale of production, internal funds are low, but investment demands are high because of decreasing return to scale. Moreover, all else equal, firms with more debt have less internal funds available for investment because of debt payments. Accordingly, small firms and firms already in debt are more constrained.

Aggregate and firm-specific productivity shocks have two offsetting effects on the financial gap. A positive shock raises internal funds, but it also raises investment demands because the shock increases the conditional mean of productivity. For firm-specific shocks, the effect on internal funds dominates, therefore more profitable firms are less constrained. For aggregate shocks, the effect on investment demands dominates, therefore firms are more constrained in economic booms.

Our first contribution concerns the role of the stochastic discount factor in driving the procyclical shadow price of external funds. Unlike firm-specific shocks, aggregate shocks can affect the stochastic discount factor, which provides a discount-rate channel through which aggregate shocks can impact capital investment. Specifically, when a positive aggregate shock hits a firm, its real investment increases because its capital stock becomes more productive (the cash-flow channel). But the positive aggregate shock also causes the aggregate discount rate to fall, which in turn causes the net present value of an additional unit of investment to go up, stimulating investment even further (the discount-rate channel). The increase in investment demands exceeds the increase in internal funds, generating a higher financial gap after the positive aggregate shock.

Our analysis explains why traditional, partial equilibrium investment models cannot generate procyclical financial constraints. These models typically assume constant discount factors. Aggregate and firm-specific shocks affect investment symmetrically, therefore firms are more constrained in bad times for the same reason why less profitable firms are more constrained. Our analysis also suggests that procyclical financial constraints should appear in general equilibrium models 
with stochastic discount factors. Indeed, Gomes, Yaron, and Zhang (2003) show that the implied shadow price of new funds is procyclical in several well-known general equilibrium models (e.g., Bernanke and Gertler 1989; Carlstrom and Fuerst 1997; Bernanke, Gertler, and Gilchrist 1999).

Our second contribution concerns the relation between financial constraints and expected returns. In our models, the shadow price of external funds is determined jointly with risk and expected returns by underlying state variables. In equilibrium, small firms, less profitable firms, and firms in debt are riskier and earn higher expected returns. But these firms are also more financially constrained, suggesting that more constrained firms are riskier and earn higher expected returns than less constrained firms. This prediction arises because the shadow price contains information on the underlying state variables that drive risk and expected returns. However, market capitalization and book-to-market contain similar information. Using computational experiments, we find that sorting on the shadow price alone generates significant average-return spreads, but the shadow price largely loses its explanatory power once we control for market capitalization and book-to-market.

We also use our explicitly-solved models as laboratories to study quantitatively the empirical determinants of the shadow price of external funds. Consistent with the evidence in Kaplan and Zingales (1997) and Whited and $\mathrm{Wu}$ (2006), our quantitative results show that firms will be more constrained financially if they have lower cash flow to assets, higher debt to assets, lower sales and sales growth, lower dividends to assets, lower liquid assets or cash to assets, and higher Tobin's $Q$. More interesting, we run a horse race between the Kaplan-Zingales index and the Whited-Wu index on our simulated data to evaluate their relative quality as empirical proxies for the shadow price of external funds. We find that, although both indexes are positively correlated with the shadow price, the Whited-Wu index appears more powerful than the Kaplan-Zingales index.

Our paper provides a comprehensive, theoretical analysis of the structural relation between financial constraints and stock returns, facilitating the interpretation of the evidence in Lamont, Polk, and Saá-Requejo (2001), Gomes, Yaron, and Zhang (2006), and Whited and Wu (2006). Our modeling of debt dynamics is heavily influenced by Hennessy and Whited (2005, 2006), but we add 
aggregate shocks and asset pricing dynamics. More generally, our work belongs to the literature that connects the cross section of returns to corporate policies and the real economy (e.g., Cochrane 1991, 1996; Berk, Green, and Naik 1999). ${ }^{2}$ We contribute to this literature by studying the impact of financial constraints and debt dynamics on risk and expected returns.

The rest of the itinerary is as follows. Section 2 constructs the dynamic models. Sections 3 and 4 present qualitative and quantitative analyses of the models, respectively. Section 5 concludes.

\section{The Dynamic Models}

We present two dynamic models of financial constraints. In Model 1, firms have no access to external equity markets, and cannot retain earnings or borrow debts. Although simplistic, this framework has been used in much of the related literature, thereby providing a natural benchmark to start our analysis. In Model 2, we allow firms to issue costly external equity, retain earnings, and borrow at a risk-free rate. When borrowing, firms face collateral constraints that limit their debt capacity.

\subsection{The Common Environment}

We first present the environment common to both Models 1 and 2 .

\section{Technology}

The production function is given by:

$$
y_{j t}=e^{x_{t}+z_{j t}} k_{j t}^{\alpha}
$$

where $y_{j t}$ and $k_{j t}$ are the output and capital stock of firm $j$ at period $t$, respectively. $0<\alpha<1$, so the production technology exhibits decreasing returns to scale. Production is subject to both an aggregate shock, $x_{t}$, and a firm-specific shock, $z_{j t}$.

The aggregate productivity shock has a stationary and monotone Markov transition function,

\footnotetext{
${ }^{2}$ An incomplete list of other examples includes Berk (1995), Gomes, Kogan, and Zhang (2003), Carlson, Fisher, and Giammarino (2004, 2006), Kogan (2004), Pástor and Veronesi (2005), Zhang (2005), Cooper (2006), and Gala (2006).
} 
denoted $Q_{x}\left(x_{t+1} \mid x_{t}\right)$, as follows:

$$
x_{t+1}=\bar{x}\left(1-\rho_{x}\right)+\rho_{x} x_{t}+\sigma_{x} \varepsilon_{t+1}^{x}
$$

where $\varepsilon_{t+1}^{x}$ is an i.i.d. standard normal shock. In our models, the aggregate shock is the driving force of economic fluctuations and systematic risk.

The firm-specific productivity shocks, denoted $z_{j t}$, are uncorrelated across firms, indexed by $j$, and have a common stationary and monotone Markov transition function, denoted $Q_{z}\left(z_{j t+1} \mid z_{j t}\right)$ :

$$
z_{j t+1}=\rho_{z} z_{j t}+\sigma_{z} \varepsilon_{j t+1}^{z}
$$

where $\varepsilon_{j t+1}^{z}$ is an i.i.d. standard normal shock. $\varepsilon_{j t+1}^{z}$ and $\varepsilon_{i t+1}^{z}$ are uncorrelated with each other for any pair $(i, j)$ with $i \neq j$. Moreover, $\varepsilon_{t+1}^{x}$ is independent of $\varepsilon_{j t+1}^{z}$ for all $j$. In our models, the firm-specific shock is the ultimate driving force of firm heterogeneity.

\section{Stochastic Discount Factor}

Following Berk, Green, and Naik (1999), we use partial equilibrium models to focus on the link between corporate policies and expected returns. The omission of consumer behavior can hopefully be compensated by firm dynamics often absent from consumption-based asset pricing models.

Specifically, we parameterize the stochastic discount factor as follows:

$$
\begin{aligned}
\log m_{t+1} & =\log \eta+\gamma_{t}\left(x_{t}-x_{t+1}\right) \\
\gamma_{t} & =\gamma_{0}+\gamma_{1}\left(x_{t}-\bar{x}\right)
\end{aligned}
$$

where $m_{t+1}$ denotes the stochastic discount factor from time $t$ to $t+1.1>\eta>0, \gamma_{0}>0$, and $\gamma_{1}<0$ are constant parameters. Equation (4) can be motivated as a reduced-form representation of the intertemporal rate of substitution for a fictitious representative consumer. Following Zhang (2005), we assume in equation (5) that $\gamma_{t}$ decreases in $x_{t}-\bar{x}$ to capture time-varying price of risk. ${ }^{3}$

\footnotetext{
${ }^{3}$ We remain agnostic about the precise economic sources driving the countercyclical price of risk. Potential sources include time-varying risk aversion in Campbell and Cochrane (1999), loss aversion in Barberis, Huang, and Santos
} 


\section{The Operating-Profit Function}

The operating-profit function for firm $j$ with capital stock $k_{j t}$, idiosyncratic productivity $z_{j t}$, and aggregate productivity $x_{t}$ is:

$$
\pi\left(k_{j t}, z_{j t}, x_{t}\right)=e^{x_{t}+z_{j t}} k_{j t}^{\alpha}-f
$$

where $f>0$ is nonnegative fixed costs of production, which must be paid every period.

\section{The Investment-Cost Function}

When investing, firms incur purchase costs and capital adjustment costs. The total investment-cost function, $\phi\left(i_{j t}, k_{j t}\right)$, is assumed to be asymmetric and quadratic:

$$
\phi\left(i_{j t}, k_{j t}\right) \equiv i_{j t}+\frac{a_{P} \mathbf{1}_{j t}^{i}+a_{N}\left(1-\mathbf{1}_{j t}^{i}\right)}{2}\left(\frac{i_{j t}}{k_{j t}}\right)^{2} k_{j t}
$$

where $\mathbf{1}_{j t}^{i} \equiv \mathbf{1}_{\left\{i_{j t} \geq 0\right\}}$ with $\mathbf{1}_{\{\cdot\}}$ being the indicator function that equals one if the event described in $\{\cdot\}$ is true and zero otherwise. We assume $a_{N}>a_{P}>0$ to capture costly reversibility (e.g., Abel and Eberly 1994, 1996; Hall 2001); intuitively, firms face higher costs per unit of adjustment in cutting than expanding their capital stocks. Zhang (2005) uses asymmetric adjustment costs to address the value premium, the stylized fact that value firms with high book-to-market ratios earn higher returns on average than growth firms with low book-to-market ratios. We instead use the neoclassical framework to address the relation between financial constraints and expected returns.

\subsection{Model 1: Dividend Nonnegativity Constraints}

Model 1 captures financial constraints by shutting down the external equity markets.

\section{Dividend Nonnegativity Constraints}

We first model financial constraints parsimoniously as follows:

$$
d_{j t} \equiv \pi\left(k_{j t}, z_{j t}, x_{t}\right)-\phi\left(i_{j t}, k_{j t}\right) \geq 0
$$

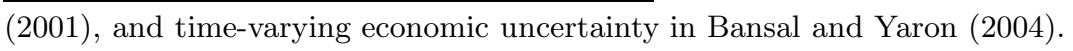


Because negative dividends are equivalent to costless external equity, equation (8) basically denies firms access to external equity. We also assume that firms cannot borrow or retain earnings. Although simplistic, the dividend constraints are standard in the literature (e.g., Whited 1992, Bond and Meghir 1994, Cooper and Ejarque 2003, Moyen 2004, Whited and Wu 2006, and Gomes, Yaron, and Zhang 2006). We therefore use equation (8) as a natural benchmark to start our analysis.

\section{Dynamic Value Maximization}

Let $v\left(k_{j t}, z_{j t}, x_{t}\right)$ denote the market value of firm $j$. Using Bellman's Principle of Optimality, we can state firm $j$ 's dynamic value-maximization problem as:

$$
v\left(k_{j t}, z_{j t}, x_{t}\right)=\max _{\left\{k_{j t+1}, i_{j t}\right\}}\left\{\pi\left(k_{j t}, z_{j t}, x_{t}\right)-\phi\left(i_{j t}, k_{j t}\right)+\mathrm{E}_{t}\left[m_{t+1} v\left(k_{j t+1}, z_{j t+1}, x_{t+1}\right)\right]\right\}
$$

subject to the equation of capital accumulation:

$$
k_{j t+1}=i_{j t}+(1-\delta) k_{j t}
$$

and the dividend nonnegativity constraint (8). The first two terms on the right-hand side of (9) reflect current dividends that equal profits minus total investment costs.

\section{The Shadow Price of New Equity}

Let $\mu_{j t} \equiv \mu\left(k_{j t}, z_{j t}, x_{t}\right)$ be the Lagrange multiplier associated with the dividend nonnegativity constraint in equation (8). The multiplier can be interpreted as the shadow price of external equity; the higher $\mu_{j t}$ is, the more financially constrained firm $j$ will be.

We show in Appendix A that:

$$
\mu_{j t}=\frac{v_{k}\left(k_{j t}, z_{j t}, x_{t}\right)}{d_{k}\left(k_{j t}, i_{j t}, z_{j t}, x_{t}\right)}-1
$$

where $v_{k}$ and $d_{k}$ denote the first-order derivatives of firm value and dividend, respectively, with respect to capital stock, $k_{j t}$. The interpretation of equation (11) is straightforward. All else equal, firms with higher $v_{k}$ are more likely to be constrained. Intuitively, firms with higher marginal value 
of capital will have higher investment demands, and therefore higher demands for external equity. Moreover, firms in which an additional unit of capital can generate more dividend or $d_{k}$ is higher are less financially constrained. This effect is again intuitive because higher internal funds alleviate the demands for external equity.

\section{Risk and Expected Excess Return}

Evaluating the value function in equation (9) at the optimum yields:

$$
v_{j t}=d_{j t}+\mathrm{E}_{t}\left[m_{t+1} v_{j t+1}\right]
$$

which is equivalent to $1=\mathrm{E}_{t}\left[m_{t+1} r_{j t+1}\right]$, where the stock return $r_{j t+1} \equiv v_{j t+1} /\left(v_{j t}-d_{j t}\right)$. Note that $v_{j t}$ is the cum-dividend firm value because it is measured before the dividend is paid out. We can further rewrite $1=\mathrm{E}_{t}\left[m_{t+1} r_{j t+1}\right]$ as the beta-pricing form (e.g., Cochrane 2001, p. 19):

$$
\mathrm{E}_{t}\left[r_{j t+1}\right]-r_{f t}=\beta_{j t} \zeta_{m t}
$$

where $r_{f t} \equiv 1 / \mathrm{E}_{t}\left[m_{t+1}\right]$ is the real interest rate from period $t$ to $t+1$, risk is defined by:

$$
\beta_{j t} \equiv \frac{-\operatorname{Cov}_{t}\left[r_{j t+1}, m_{t+1}\right]}{\operatorname{Var}_{t}\left[m_{t+1}\right]}
$$

and the price of risk is given by $\zeta_{m t} \equiv \operatorname{Var}_{t}\left[m_{t+1}\right] / \mathrm{E}_{t}\left[m_{t+1}\right]$.

\subsection{Model 2: Collateral Constraints}

Although useful as a first stab at dynamic modeling of financial constraints, Model 1 has several unrealistic features. In particular, firms cannot issue equity, borrow debt, or retain earnings. We now introduce a more realistic but more complex model in which the unpalatable assumptions in Model 1 are relaxed. In this alternative model, financial constraints are captured as collateral constraints on the maximum amount of debt that firms can borrow. 


\section{The Collateral Constraints}

For tractability, we follow Hennessy and Whited (2005) and model only single-period debt. Let $b_{j t+1}$ represent the face value of one-period debt chosen by firm $j$ at beginning of period $t$ with payment due at the beginning of period $t+1$. Positive values of $b_{j t+1}$ imply that the firm is borrowing and negative values of $b_{j t+1}$ imply that the firm is saving or retaining earnings.

When borrowing, firms face collateral constraints which require that the liquidation value of capital net of depreciation is at least as high as the promised debt payment:

$$
b_{j t+1} \leq s(1-\delta) k_{j t+1}
$$

where $0<s<1$ is a constant parameter. Effectively, we assume that in the event of liquidation, capital can only be sold at a depressed price, $s<1$. The portion $(1-s)$ of capital is lost in the liquidation process due to, for example, bankruptcy costs.

Because the collateral constraints guarantee that lenders always get repaid in full, all corporate debts are riskless and their interest rates equal to the risk-free rate $r_{f t}$. Accordingly, by committing to repay $b_{j t+1}$ at the beginning of $t+1$, firm $j$ obtains cash inflow $b_{j t+1} / r_{f t}$ at the beginning of period $t$. For tractability, we do not model defaultable bonds.

\section{Retained Earnings}

Because of the collateral constraints, firms are not indifferent between savings and cash distributions. If a firm distributes a dollar to the shareholders today, this dollar invested on the Treasury bills will be worth $r_{f t}$ next period. But the cost of distributing this dollar equals the cost of borrowing this dollar, $r_{f t}$, plus the shadow price of an additional dollar of borrowing when the collateral constraints are binding. Firms thus strictly prefer savings to distributions. If the interest rate earned by corporate savings, denoted $r_{s t}$, equals the risk-free borrowing rate, $r_{f t}$, firms will save all the free cash flow and never distribute.

In practice, firms do distribute cash to shareholders because there are costs associated with 
holding cash. Graham (2000) report that cash retentions are tax-disadvantaged because tax rates generally exceed tax rates on interest income for bondholders. To capture this effect, we follow Hennessy, Levy, and Whited (2005) and assume that the saving rate is strictly less than the borrowing rate, i.e., $r_{s t}<r_{f t}$. Specifically:

$$
r_{s t}=r_{f t}-\kappa
$$

where $\kappa>0$ is a constant wedge between borrowing and saving rates. Cooley and Quadrini (2001) provide further justification for $r_{s t}<r_{f t}$. Suppose the two interest rates are equal, then in the economy with financial frictions, firms would strictly prefer to reinvest profits. Doing so would generate an excessive supply of loanable funds and the subsequent reduction in the saving rate, $r_{s t}$.

For notational simplicity, let $\mathbf{1}_{j t+1}^{b} \equiv \mathbf{1}_{\left\{b_{j t+1} \geq 0\right\}}$ be the indicator function that equals one if firm $j$ borrows new debt at time $t$ and zero otherwise. Because $b_{j t+1}$ is a choice variable, $\mathbf{1}_{j t+1}^{b}$ is known at the beginning of time $t$. Further, we let

$$
\iota_{j t} \equiv \mathbf{1}_{j t+1}^{b} r_{f t}+\left(1-\mathbf{1}_{j t+1}^{b}\right) r_{s t}
$$

denote the interest rate applicable to firm $j$ from time $t$ to time $t+1$, known at the beginning of time $t$.

\section{Costly External Equity}

When the sum of the investment costs, $\phi\left(i_{j t}, k_{j t}\right)$, and promised debt repayment, $b_{j t}$, exceeds the sum of internal funds, $\pi_{j t}$, and cash inflows from issuing new debt, $b_{j t+1} / \iota_{j t}$, the firm can raise new equity capital, $e_{j t}$, to compensate for the financial slack:

$$
e_{j t} \equiv \max \left(\phi\left(i_{j t}, k_{j t}\right)+b_{j t}-\pi\left(k_{j t}, z_{j t}, x_{t}\right)-\frac{b_{j t+1}}{\iota_{j t}}, 0\right)
$$

Motivated by empirical evidence (e.g., Smith 1977, Lee, Lochhead, Ritter, and Zhao 1996, and Altinkilic and Hansen 2000), we assume that there are costs of issuing external equity. We specify 
the total cost of issuing equity as:

$$
\lambda\left(e_{j t}, k_{j t}\right)=\lambda_{0} \mathbf{1}_{j t}^{e}+\frac{\lambda_{1}}{2}\left(\frac{e_{j t}}{k_{j t}}\right)^{2} k_{j t}
$$

where $\lambda_{0}, \lambda_{1}>0$ and $\mathbf{1}_{j t}^{e} \equiv \mathbf{1}_{\left\{e_{j t}>0\right\}}$ is the indicator function that equals one if firm $j$ issues external equity and zero otherwise. The first term in the right hand side of equation (18) captures the fixed costs of issuing equity and the second term captures the convex, variable costs.

On the other hand, when the sum of investment costs and debt repayments is lower than the sum of internal funds and cash inflows from new debt, firms distribute the difference back to shareholders. We assume that firms do not incur any costs when distributing cash. We do not model specific forms of the payout, cash dividends or open market share repurchases; the model only pins down the total amount of payout.

\section{Market Value of Equity, Risk, and Expected Returns}

Define the effective dividend accrued to the shareholders as:

$$
o_{j t} \equiv \pi\left(k_{j t}, z_{j t}, x_{t}\right)+\frac{b_{j t+1}}{\iota_{j t}}-\phi\left(i_{j t}, k_{j t}\right)-b_{j t}-\lambda\left(e_{j t}, k_{j t}\right)
$$

$o_{j t}$ can be negative because the new equity $e_{j t}$ from equation (17) can be positive.

Let $v\left(k_{j t}, b_{j t}, z_{j t}, x_{t}\right)$ denote the market value of equity for firm $j$. Using Bellman's Principle of Optimality, we can formulate its dynamic value-maximization problem as:

$$
v\left(k_{j t}, b_{j t}, z_{j t}, x_{t}\right)=\max _{\left\{i_{j t}, k_{j t+1}, b_{j t+1}\right\}}\left\{o_{j t}+\mathrm{E}_{t}\left[m_{t+1} v\left(k_{j t+1}, b_{j t+1}, z_{j t+1}, x_{t+1}\right)\right]\right\}
$$

subject to the collateral-constraint equation (14) and the capital-accumulation equation (10).

The definition of risk and expected excess return in Model 2 is similar to that in Model 1. Evaluating the value function in equation (20) at the optimum yields $v_{j t}=o_{j t}+\mathrm{E}_{t}\left[m_{t+1} v_{j t+1}\right]$ or equivalently, $1=\mathrm{E}_{t}\left[m_{t+1} r_{j t+1}\right]$, where the stock return $r_{j t+1} \equiv v_{j t+1} /\left(v_{j t}-o_{j t}\right)$. With $r_{j t+1}$ defined, expected excess returns and risk can be defined in a similar way as equations (12) and (13) in Model 1. 


\section{The Shadow Price of New Debt}

Let $\nu_{j t} \equiv \nu\left(k_{j t}, b_{j t}, z_{j t}, x_{t}\right)$ be the Lagrange multiplier associated with the collateral constraint in equation (14), or the shadow price of new debt. The higher $\nu_{j t}$ is, the more financially constrained firms will be. As shown in Appendix A, the first-order condition with respect to $b_{j t+1}$ implies that:

$$
\nu_{j t}=\frac{1}{r_{f t}} \lambda_{e}\left(e_{j t}, k_{j t}\right) \mathbf{1}_{j t}^{e}-\mathrm{E}_{t}\left[m_{t+1} \lambda_{e}\left(e_{j t+1}, k_{j t+1}\right) \mathbf{1}_{j t+1}^{e}\right]
$$

where $\lambda_{e}\left(e_{j t}, k_{j t}\right)$ is the first derivative of $\lambda$ with respect to $e_{j t}$ when $e_{j t}>0$.

The interpretation of equation (21) is straightforward. Because debt and equity are two sources of external funds, the shadow price of new debt depends on the tradeoff between debt and equity finance. On the one hand, one additional unit of debt saves firm $j$ an amount that equals the marginal cost of equity finance, $\lambda_{e}\left(e_{j t}, k_{j t}\right) \mathbf{1}_{j t}^{e}$. This marginal benefit of new debt must be discounted by $r_{f t}$ because the firm only raises $1 / r_{f t}$ dollar at the beginning of time $t$ by agreeing to pay one additional unit of debt, $b_{j t+1}$, at the beginning of period $t+1$. On the other hand, there are costs associated with borrowing one additional unit of debt because it must be repaid. Having to repay the debt at the beginning of period $t+1$ means that the firm must pay the marginal cost of equity finance $\lambda_{e}\left(e_{j t+1}, k_{j t+1}\right) \mathbf{1}_{j t+1}^{e}$. This (stochastic) cost of borrowing must be discounted back to the beginning of time $t$, as shown in the second term in equation (21).

\section{Qualitative Analysis}

Section 3.1 calibrates the model parameters and discusses briefly the numerical issues involved in solving the models. Section 3.2 and 3.3 then provide qualitative analysis on the solutions to Models 1 and 2, respectively. Appendix B details the numerical algorithms.

\subsection{Calibration}

We calibrate all model parameters at the monthly frequency to be consistent with the empirical literature. Table 1 reports the parameters. Following Gomes (2001) and Zhang (2005), we set the 
capital share $\alpha$ to be 0.30 and the monthly rate of depreciation $\delta$ to be 0.01 , which implies an annual rate of $12 \%$. The persistence of aggregate productivity process, $\rho_{x}$, is set to be $0.95^{1 / 3}=0.983$, and its conditional volatility, $\sigma_{x}, 0.007 / 3=0.0023$. With the first-order autoregressive specification for $x_{t}$ in equation (2), these monthly values correspond to 0.95 and 0.007 at the quarterly frequency, respectively, consistent with Cooley and Prescott (1995).

Following Zhang (2005), we pin down the three parameters governing the stochastic discount factor, $\eta, \gamma_{0}$, and $\gamma_{1}$ to match three aggregate return moments: the average Sharpe ratio; the average real interest rate; and the volatility of real interest rate. ${ }^{4}$ This procedure yields $\eta=0.994, \gamma_{0}=50$, and $\gamma_{1}=-1000$, which generate an average Sharpe ratio of 0.41 , an average annual real interest rate of $2.2 \%$, and an annual volatility of real interest rate of $2.9 \%$, similar to those in the data.

The adjustment-cost parameters, $a_{P}$ and $a_{N}$, can be interpreted as the periods required to expanding and cutting the capital stock, respectively, given one unit of change in the marginal $q$. We set $a_{P}=15$ and $a_{N}=150$ months, respectively, close to the average estimates in the empirical investment literature. To calibrate the persistence $\rho_{z}$ and the conditional volatility $\sigma_{z}$ for the firm-specific productivity in equation (3), we set $\rho_{z}=0.96$ and $\sigma_{z}=0.10$. These values are chosen to obtain an average annual cross-sectional volatility of individual stock returns around $27 \%$. The fixed cost of production $f$ is set to be 0.0275 .

There are also three parameters specific to Model 2, including the liquidation cost parameter $s$, the fixed floatation-cost parameter $\lambda_{0}$, and the flow floatation-cost parameter $\lambda_{1}$. We let $s=0.85$ which implies proportional liquidation costs of $15 \%$, largely consistent with available evidence. For example, Altman (1984) estimates the average bankruptcy costs to be $12 \%$ of the firm value three years prior to the petition date and $16.7 \%$ at the petition date. Andrade and Kaplan (1998) estimate direct and indirect financial distress costs to be between 10-20\% of firms value. And Hennessy and Whited (2006) estimate bankrupt costs to be $10.4 \%$ of the value of assets with a $p$-value of

\footnotetext{
${ }^{4}$ From equations (4) and (5), the real interest rate $r_{f t}$ and the maximum Sharpe ratio $S_{t}$ can be written as $r_{f t}=1 / \mathrm{E}_{t}\left[m_{t+1}\right]=\frac{1}{\eta} e^{-\mu_{m}-\frac{1}{2} \sigma_{m}^{2}}$ and $S_{t}=\sigma_{t}\left[m_{t+1}\right] / \mathrm{E}_{t}\left[m_{t+1}\right]=\sqrt{e^{\sigma_{m}^{2}}\left(e^{\sigma_{m}^{2}}-1\right)} / e^{\sigma_{m}^{2} / 2}$, respectively, where $\mu_{m} \equiv\left[\gamma_{0}+\gamma_{1}\left(x_{t}-\bar{x}\right)\right]\left(1-\rho_{x}\right)\left(x_{t}-\bar{x}\right)$ and $\sigma_{m} \equiv \sigma_{x}\left[\gamma_{0}+\gamma_{1}\left(x_{t}-\bar{x}\right)\right]$.
} 
6\%. For the equity financing costs, we calibrate the fixed floatation cost $\lambda_{0}$ to be 0.08 and the flow floatation cost $\lambda_{1}$ to be 0.025 . These parameter values are the same as those in Gomes (2001), who estimate these parameters based on Smith (1977).

Armed with these parameter values, we use value function iteration techniques to solve the models. It is worthwhile pointing out that solving the models, especially Model 2, is technically challenging. (The solution algorithm for Model 2 coded in MATLAB takes about 30 days to run on a Dell workstation with dual Xeon 2Ghz CPUs and 1.00 GB of RAM.) The reason is that Model 2 is subject to the "curse of dimensionality" (e.g., Judd 1998, p. 430). In an effort to be reasonably realistic, Model 2 has in total four state variables including capital stock $k_{j t}$, current-period debt $b_{j t}$, firm-specific productivity $z_{j t}$, and aggregate productivity $x_{t}$. Further complicating the solution algorithm are the two control variables, next-period capital $k_{j t+1}$ and next-period debt $b_{j t+1}$.

By way of contrast, Hennessy and Whited (2005) have two controls and three states, and Hennessy and Whited (2006) have two controls and two states. More important, Hennessy and Whited calibrate and solve their models in annual frequency, but our asset pricing applications require that we calibrate and solve our models in monthly frequency. The high frequency lowers the speed of convergence of our solution algorithm by an order of magnitude relative to their algorithm. Another informative comparison is with Zhang (2005), who solves his model with four states in monthly frequency, but he has only one control. Despite the curse of dimensionality, we opt to use the value function iteration algorithm because of its well-known stability and precision.

\subsection{Model 1: Qualitative Analysis}

Using the numerical solution to Model 1, we plot and discuss the value and policy functions, risk and expected excess returns, and the multiplier as functions of the underlying state variables.

Because there are three state variables in Model 1 (capital stock $k_{j t}$, aggregate productivity $x_{t}$, and firm-specific productivity $z_{j t}$ ), Panels $\mathrm{A}$ and $\mathrm{C}$ in Figures 1 and 2 plot the variables against $k_{j t}$ and $z_{j t}$, while fixing $x_{t}$ at its long-run average level $\bar{x}$. Each one of these panels has a set of curves 
corresponding to different values of $z_{j t}$, and the arrow in each panel indicates the direction along which $z_{j t}$ increases. Panels B and D then plot the variables against $k_{j t}$ and $x_{t}$ only, while fixing $z_{j t}$ at its long run average level $\bar{z}_{j}=0$. Each one of these panels has a set of curves corresponding to different values of $x_{t}$, and the arrow in each panel indicates the direction along which $x_{t}$ increases.

From Panels A and B in Figure 1, firms with relatively small capital stocks and high firm-specific productivity have relatively high market-to-book ratios. These predictions are largely consistent with the empirical evidence in Fama and French $(1992,1995)$. Moreover, firms have relatively high market-to-book ratios when the general economic conditions are relatively good, consistent with the evidence on time series predictability associated with aggregate book-to-market (e.g., Kothari and Shanken 1997, Pontiff and Schall 1999).

The optimal investment-to-capital ratio largely inherits the properties of the market-to-book ratio. From Panels $\mathrm{C}$ and D in Figure 1, firms with relatively small capital stocks and firms with relatively high firm-specific profitability invest more relative to their capital stocks and grow faster, consistent with the evidence in Fama and French (1995). Because investment-to-capital is independent of capital stock with constant return to scale, the driving force behind our model-implied inverse relation between investment-to-capital and capital stock is therefore decreasing return to scale.

\section{The Multiplier}

The multiplier associated with the dividend nonnegativity constraint in equation (11) is at the center of our analysis. Panel A of Figure 2 shows that the multiplier decreases in capital stock, $k_{j t}$, and in firm-specific productivity, $z_{j t}$, suggesting that financial constraints are more binding for small and less profitable firms. These patterns are intuitive and are consistent with the evidence (e.g., Chan and Chen 1991; Gertler and Gilchrist 1994; Perez-Quiros and Timmermann 2000; Lamont, Polk, and Saá-Requejo (2001); Whited and Wu 2006). Moreover, Panel B shows that the multiplier increases in the aggregate productivity, $x_{t}$, suggesting that financial constraints are more binding when the aggregate economic conditions are relatively good. Although somewhat surprising, this 
pattern is consistent with the evidence in Gomes, Yaron, and Zhang (2006).

More important, why does the shadow price of new equity respond negatively to firm-specific shocks but positively to aggregate shocks? The crux is the stochastic discount factor, $m_{t+1}$, modeled in equation (4). Aggregate shocks affect $m_{t+1}$, but firm-specific shocks do not.

Intuitively, the multiplier for a given firm is determined by the gap between its investment demands and internal funds. The firm is financially constrained if its investment demands exceed internal funds. The higher the gap, the higher the shadow price of external funds, and the more constrained the firm will be.

Productivity shocks have two offsetting effects on the financial gap. A positive shock increases internal funds and thereby reduces the gap, but it also increases investment demands and thereby increases the gap. For firm-specific shocks, the first effect dominates quantitatively, therefore firms with higher firm-specific productivity are less constrained.

The two offsetting effects also apply to aggregate shocks. Most important, aggregate shocks differ from firm-specific shocks because aggregate shocks affect the stochastic discount factor. Aggregate shocks can therefore affect investment demands through an additional, discount-rate channel. Specifically, when a positive aggregate shock hits a firm, it will increase investment demands through the usual cash flow channel because its capital stock becomes more productive. But a positive aggregate shock also gives rise to a higher discount factor, $m_{t+1}$, or loosely speaking, a lower discount rate, $1 / m_{t+1}$. This discount-rate effect in turn increases the expected continuation value, $\mathrm{E}_{t}\left[m_{t+1} v\left(k_{j t+1}, z_{j t+1}, x_{t+1}\right)\right]$ in equation (9), stimulating investment demands even further. The increase in investment demands dominates quantitatively the increase in internal funds from the positive aggregate shock. Consequently, the financial gap increases.

As a corollary, the discount-rate channel on the multiplier should disappear without the stochastic discount factor. And the multiplier should be countercyclical when $m_{t+1}$ is constant. This outcome is indeed what happens in the model. Panels C and D in Figure 2 plot the multiplier against underlying state variables in Model 1 with a constant discount factor, $\gamma_{0}=\gamma_{1}=0$. From Panel D, 
the multiplier now decreases in the aggregate productivity $x_{t}$. Effectively, with the constant discount factor, aggregate and firm-specific productivity shocks enter the value-maximization problem of firms symmetrically. In the same way that firms with low firm-specific productivity are more constrained, firms are more constrained when aggregate economic conditions are relatively bad. ${ }^{5}$

\section{Risk and Expected Excess Return}

Figure 3 plots expected excess returns and risk, defined in equations (12) and (13), respectively. From Panels A and C, firms with small scale of production and low firm-specific productivity are riskier and earn higher expected returns than firms with large scale of production and high firmspecific productivity. More important, as shown in Panel A of Figure 2, small and less profitable firms are also most likely to be financially constrained. Collectively, the panels show that more financially constrained firms are riskier and earn higher expected returns than less financially constrained firms. These predictions lend support to Chan and Chen (1991) and Perez-Quiros and Timmermann (2000). These authors interpret their evidence as suggesting that small firms and relatively unprofitable firms earn higher average returns because these firms are more adversely affected by lower liquidity in tight credit market conditions.

However, market value of equity and book-to-market are determined jointly and endogenously with the multiplier by the underlying state variables in equilibrium. To quantify the incremental effects of the multiplier on risk and expected returns independent of size and book-to-market, we must use computational experiments. We take up this task in Section 4.

Finally, Panels B and D in Figure 3 show that conditional betas, $\beta_{j t}$, increase but expected excess returns decrease with the aggregate productivity, $x_{t}$. These two effects can be reconciled by the countercyclical price of risk, $\zeta_{m t}$, implied by the pricing kernel in equation (4). Although the amount of risk is high in good times, the price of risk is low, giving rise to low expected excess returns.

\footnotetext{
${ }^{5}$ In a previous version of this paper, we also report that market-to-book and investment-to-capital in the constantdiscount-factor case are much less sensitive to aggregate shocks than their counterparts in the benchmark stochasticdiscount-factor case. These results are omitted for brevity but are available upon request.
} 


\subsection{Model 2: Qualitative Analysis}

We now ask whether our central insights on the determinants of the multiplier, risk, and expected returns from Model 1 are robust if we relax its restrictive assumptions. The answer is largely affirmative. To this end, we turn to Model 2 with collateral constraints.

Panels A and B of Figure 4 show that, in Model 2, the market-to-book ratio, $v_{j t} / k_{j t}$, is strictly decreasing with the current-period debt, $b_{j t}$. This result is expected because the Envelope Theorem implies that $v_{b}\left(k_{j t}, b_{j t}, z_{j t}, x_{t}\right)=-\left(1+\lambda_{e}\left(e_{j t}, k_{j t}\right) \mathbf{1}_{j t}^{e}\right)<0$. Further, this pattern is consistent with the inverse relation between market-to-book and leverage ratios documented by, for example, Smith and Watts (1992). From Panels C and D, firms with large amount of debt invest less than firms with small amount of debt and firms with corporate liquidity, a pattern often called "debt overhang" (e.g., Myers 1977; Hennessy 2004). ${ }^{6}$

Figure 5 reports the optimal next-period-debt-to-capital ratio, $b_{j t+1} / k_{j t}$, as functions of the underlying state variables. Several intuitive patterns arise. First, firms with relatively small scale of production, $k_{j t}$, and low firm-specific profitability, $z_{j t}$, borrow more (Panel A). Second, firms also borrow more in good times (Panel B). Third, the debt-to-capital ratio is persistent because firms with more debt in the current period are likely to borrow more, and firms with more corporate savings are likely to save more (Panels C and D). Fourth, given capital stock, more profitable firms save more and borrow less (Panels A and C). Finally, depending on their current debt levels, firms tend to save more and borrow more in economic booms (Panel D). Although optimal debt policy is not the focus of our study, we notice that these predictions are largely consistent with empirical evidence on debt (e.g., Titman and Wessels 1988; Smith and Watts 1992; Rajan and Zingales 1995).

\section{The Multiplier}

The properties of the multiplier in Model 2 are largely similar to those in Model 1. From Panels A and B of Figure 6, the shadow price of new debt, $\nu_{j t}$, is decreasing with capital stock, $k_{j t}$, and

\footnotetext{
${ }^{6}$ We also find that, in Model 2, both market-to-book and investment-to-capital are decreasing and convex in capital stock, and are both increasing in aggregate and firm-specific productivity. These results are similar to those from Model 1, and are omitted to avoid redundancy with Figure 1. Details are available upon request.
} 
weakly decreasing firm-specific productivity, $z_{j t}$. Panels B and D show that the multiplier $\nu_{j t}$ is weakly increasing in aggregate productivity $x_{t}$, suggesting that firms are again more constrained in good times. From Panels $\mathrm{C}$ and D, firms with positive corporate liquidity (and low current debt levels) are unconstrained financially, and firms with high current debt levels are more constrained. Moreover, the behavior of new-equity-to-capital, $e_{j t} / k_{j t}$, is very similar to that of the multiplier. Firms with small capital stock and large debt overhang issue more equity, but the new equity is much less sensitive to either aggregate or firm-specific productivity shocks. ${ }^{7}$

More important, although the multipliers from Models 1 and 2 share similar properties, comparing Figures 2 and 6 shows that the multiplier in Model 2 appears much less sensitive quantitatively to changes in aggregate and firm-specific productivity shocks. This pattern is noteworthy because, as shown in Table 1, 12 out of 16 parameters in Model 2 are directly from Model 1. The remaining four parameters are specific to the structure in Model 2. The differences in quantitative magnitude are therefore more likely to be driven by structural differences, not different parameters across the models. Intuitively, the collateral constraints in Model 2 restrict only debt financing; firms can still finance investments with new equity. In contrast, the dividend nonnegativity constraints in Model 1 are much more restrictive, effectively ruling out all new funds, debt or equity. It is therefore natural that the multiplier from Model 1 is more sensitive to shocks than the multiplier from Model 2.

\section{Debt, Liquidity, Risk, and Expected Excess Returns}

In Model 2, the structural relations between risk and expected excess returns on the one side, and capital stock and productivity shocks on the other, are similar to those in Model 1. Specifically, firms with small capital stocks and low firm-specific productivity are riskier and earn higher expected excess returns than firms with large capital stocks and high firm-specific productivity. ${ }^{8}$ As shown in Figure 6, small and less profitable firms in Model 2 are also more constrained financially. Therefore, as in Model 1, Model 2 also predicts that more constrained firms are riskier and earn

\footnotetext{
${ }^{7}$ The details are omitted to avoid redundancy with Figure 6, but are available upon request.

${ }^{8}$ The details are omitted to avoid redundancy with Figure 3, but are available upon request.
} 
higher expected returns than less constrained firms.

More interesting, Model 2 allows us to study how current-period debt, $b_{j t}$, affects risk and expected returns. From all panels in Figure 7, all else equal, firms with high current debt are riskier and earn higher expected returns than firms with low current debt and firms with corporate savings. The positive relation between current debt and risk and expected returns is even more dramatic for less profitable firms (Panels A and C). Further, because Figure 6 shows that firms with high current debt and low profitability are more constrained financially, Figure 7 reinforces our conclusion that more constrained firms are riskier and earn higher expected returns than less constrained firms.

\section{Quantitative Implications}

We now study quantitative implications of our models. We continue to focus on two key issues, the relation between financial constraints and stock returns and the cyclicality of financial constraints.

Our experiment design follows that of Kydland and Prescott (1982) and Berk, Green, and Naik (1999). We simulate 100 artificial panels, each of which has 3000 firms and 480 months. The sample size is similar to that used in empirical studies based on the CRSP-COMPUSTATE merged dataset. We implement a variety of empirical procedures on each artificial panel and report the acrosssimulation averaged results. Whenever possible, we compare model moments with those in the data.

\subsection{Financial Constraints and Stock Returns}

We first look at the quantitative relations between the multipliers and average returns. Using the Fama and French (1993) portfolio approach, we construct portfolios by sorting on the multipliers, with and without controlling for size and book-to-market. Because the multipliers are the precise measures of financial constraints in our models, our results can help interpret the evidence in Lamont, Polk, and Saá-Requejo (2001) and Whited and Wu (2006). 


\section{One-Way Sort}

Table 2 reports the average monthly stock returns for ten portfolios sorted annually on the multipliers in simulated panels. Besides Models 1 and 2 reported in Panels A and B, we also report results from two alternative calibrations of Model 2. Panel $\mathrm{C}$ considers the high-liquidation-cost case for Model 2, in which the liquidation value per unit of capital, $s$, is reset to be 0.70 , lower than its benchmark calibration of 0.85 . We consider this case because Hennessy and Whited (2005) estimate the parameter $s$ to be 0.59 , albeit with a high $p$-value of 0.35 . Panel $\mathrm{D}$ considers the low-fixed-floatation-cost case for Model 2, in which the fixed floatation cost parameter, $\lambda_{0}$, is reset to be 0.02 . Between the benchmark and the two alternative cases of Model 2, we cover a broad range of empirically plausible parameter values for $s$ and $\lambda_{0} \cdot{ }^{9}$

From Panel A of Table 2, the one-way sort on the multiplier, $\mu_{j t}$, in Model 1 generates a positive relation between the multiplier and average returns. The average value-weighted return increases monotonically from $0.65 \%$ per month for the low-multiplier (least constrained) portfolio to $1.24 \%$ per month for the high-multiplier (most constrained) portfolio. And the average-return difference between the two extreme deciles is $0.59 \%$ with a significant $t$-statistic of 5.11 . Using equally-weighted returns yields a similar return spread of $0.57(t$-statistic $=5.13)$.

As shown in Panel B of Table 2, sorting on the multiplier, $\nu_{j t}$, from Model 2 also produces a positive, monotonic relation between the multiplier and average returns. However, the averagereturn spread between the two extremes is only $0.30 \%$ per month $(t$-statistic $=4.42)$ in the benchmark case of Model 2, only about one half of the return spread in Model 1. This quantitative result is consistent with our earlier observation that the multiplier is less sensitive to shocks in Model 2 than that in Model 1. The reason is that firms in Model 2 have multiple sources of external finance, and are more flexible financially than firms in Model 1. Finally, from Panels C and D, raising the liquidation-cost parameter and lowering the fixed-floatation-cost parameter both serve to increase

\footnotetext{
${ }^{9}$ We have also tried comparative statics for the cases with symmetric adjustment cost, $a_{P}=a_{N}=15$, low fixed cost of production, $f=0.025$, high fixed cost of production, $f=0.030$, low conditional volatility of firm-specific shock, $\sigma_{z}=0.075$, and high conditional volatility of firm-specific shock, $\sigma_{z}=0.125$. Our results are basically unchanged.
} 
somewhat the average-return spread between the most-constrained and the least-constrained portfolios. And our basic conclusion regarding the positive multiplier-return relation is unchanged.

\section{Controlling for Size and Book-to-Market}

Using their respective measures of financial constraints, Lamont, Polk, and Saá-Requejo (2001) and Whited and $\mathrm{Wu}$ (2006) document that, after controlling for market capitalization, the averagereturn spread between the most constrained and the least constrained firms is statistically indistinguishable from zero. We now ask whether our models are consistent with this finding.

Specifically, we conduct on artificial panels two-way sorts on the multiplier- $\mu_{j t}$ from Model 1 and $\nu_{j t}$ from Model 2 - and the market capitalization, measured as the ex-dividend market value of equity $-v_{j t}-d_{j t}$ in Model 1 and $v_{j t}-o_{j t}$ in Model 2. Following Lamont, Polk, and Saá-Requejo (2001) and Whited and Wu (2006), we define small-cap firms (S), mid-cap firms (M), and large-cap firms (L) as firms in the bottom $40 \%$, the middle $20 \%$, and the top $40 \%$ of the sample sorted on the market capitalization, respectively. Similarly, low-, middle-, and high-multiplier portfolios contain firms in the bottom $40 \%(\mathrm{~L})$, the middle $20 \%(\mathrm{M})$, and the top $40 \%(\mathrm{H})$ of the sample sorted on the multiplier, respectively. We then define the average high-multiplier portfolio as HIGHFC $=$ $(\mathrm{BH}+\mathrm{MH}+\mathrm{SH}) / 3$, and the average low-multiplier portfolio as $\mathrm{LOWFC}=(\mathrm{BL}+\mathrm{ML}+\mathrm{SL}) / 3$, and the financial constraints factor as FC $=$ HIGHFC - LOWFC.

Table 3 reports the model-implied average returns of the two-way sorted portfolios in excess of the risk-free rate, $r_{f t}$, and compares the model moments with the data moments. From the last two columns of the table, Lamont, Polk, and Saá-Requejo (2001) and Whited and Wu (2006) estimate the average return of $\mathrm{FC}$ to be $-0.13 \%$ per month $(t$-statistic $=-1.17)$ and $0.18 \%(t$-statistic $=$ 0.95), respectively. (The $t$-statistic for the average FC-return from Lamont et al. is calculated by the authors based on the information reported in their Table 5.) The average FC return in Model 1 is $0.42 \%$ per month $(t$-statistic $=2.05)$. And Model 2 appears to do a better job in matching the data moments; its implied average FC return is $0.19 \%(t$-statistic $=0.76)$ in the benchmark 
parametrization. Changing the liquidation-cost parameter and the fixed-floatation-cost parameter does not materially affect our quantitative results on the financial constraints factor.

A natural question arises: Why does the relation between financial constraints and average returns appear significant in the one-way sort but largely insignificant in the two-way sort? The reason is that risk and expected returns are determined jointly with other endogenous variables such as size, book-to-market, and the multipliers by the underlying state variables. In Model 1, firms differ in capital stock $k_{j t}$ and firm-specific productivity $z_{j t}$. In Model 2, firms also differ in current debt, $b_{j t}$. The cross section of risk and expected returns is ultimately determined by these firm-specific state variables, and the cross section also varies over time, depending on aggregate productivity, $x_{t}$ (see Figures 3 and 7 ). The multipliers are correlated with risk and expected returns because they contain information about the state variables that determine risk and expected returns. More important, the information in the multipliers is not all independent of the information in size and book-to-market because of their joint determination.

Table 4 shows that size and book-to-market in our models largely subsume the effects of financial constraints on risk and expected returns. Using simulated data, the table reports the Fama-MacBeth (1973) monthly cross-sectional regressions of stock returns, $r_{j t+1}$, from the beginning of time $t$ to the beginning of time $t+1$, onto the multiplier, size, and book-to-market equity, all measured at the beginning of time $t$. Size is measured as the logarithm of the market value of equity, and book-to-market equity is measured as $\ln \left[k_{j t} /\left(v_{j t}-d_{j t}\right)\right]$ in Model 1 and $\ln \left[\left(k_{j t}-b_{j t}\right) /\left(v_{j t}-o_{j t}\right)\right]$ in Model 2. The tables reports that the slopes of the multipliers are all positive and significant in univariate regressions, but become insignificant and even slightly negative in multiple regressions once we control for size and book-to-market equity.

\subsection{Financial Constraints, Firm Characteristics, and Business Cycles}

Because the shadow price of new funds is unobservable in the data, researchers are forced to use observable firm characteristics to serve as proxies for financial constraints. In the model simula- 
tions, however, we can calculate the Lagrange multipliers associated with financial constraints as precise measures of the shadow prices of new funds. It is therefore interesting to ask, using our theoretical models as natural laboratories, how well the characteristics commonly used in practice can proxy for financial constraints. The answer is fairly positive.

The first set of characteristics we study is motivated from Whited and Wu (2006), who use cash flow to assets $\left(C F_{j t}\right.$, measured as $\pi_{j t} / k_{j t}$ in both models); debt to assets $\left(T L T D_{j t}\right.$, measured as $b_{j t} \mathbf{1}_{j t}^{b} / k_{j t}$ in Model 2, undefined in Model 1); the logarithm of assets ( $L N T A_{j t}$, measured as $\left.\log \left(k_{j t}\right)\right)$; sales growth $\left(S G_{j t}\right.$, measured as $\left.y_{j t} / y_{j t-1}\right)$; and a dividend dummy $\left(D I V P O S_{j t}\right.$, which takes the value of one if $d_{j t}>0$ in Model 1 and if $o_{j t}>0$ in Model 2). Whited and Wu estimate the Lagrange multiplier on a dividend nonnegativity constraint in a framework similar to Model 1, and define the estimated multiplier as the Whited-Wu $(W W)$ index of financial constraints: ${ }^{10}$

$$
W W_{j t}=-0.091 C F_{j t}-0.062 D I V P O S_{j t}+0.021 T L T D_{j t}-0.044 L N T A_{j t}-0.035 S G_{j t}
$$

Panel A of Table 5 reports Fama-MacBeth (1973) cross-sectional regressions of the Lagrange multipliers onto contemporaneous firm characteristics motivated from Whited and $\mathrm{Wu}$ (2006). Consistent with their evidence, our simulations show that firms are more constrained financially if they have lower ratios of cash flow to assets, higher ratios of debt to assets, lower sales, lower contemporaneous sales growth, and zero rather than positive dividend payments. Moreover, the slope coefficients of these characteristics are reasonably close to those reported in the data.

We also consider a set of firm characteristics used by Lamont, Polk, and Saá-Requejo (2001) to proxy for financial constraints, characteristics in turn motivated from Kaplan and Zingales (1997). The list includes cash flow to assets $\left(C F_{j t}\right)$, debt to assets $\left(T L T D_{j t}\right)$, dividends to assets $\left(T D I V_{j t}\right.$, measured as $d_{j t} / k_{j t}$ in Model 1 , and $o_{j t}\left(1-\mathbf{1}_{j t}^{e}\right) / k_{j t}$ in Model 2), liquid assets or cash to

\footnotetext{
${ }^{10}$ Whited and $\mathrm{Wu}(2006)$ also use industry sales growth in their financial constraints index. We do not use this variable in our simulations because our one-sector models provide no cross-sectional variations in industry sales growth. If we include this term in the estimation, it will simply be absorbed into the intercept term. Our models can equivalently be interpreted as multi-sector models by treating firm-specific shocks as industry shocks. But then industry sales growth coincides with firm-level sales growth, $S G_{j t}$.
} 
assets, $\left(C A S H_{j t}\right.$, measured as $-b_{j t}\left(1-\mathbf{1}_{j t}^{b}\right) / k_{j t}$ in Model 2, undefined in Model 1), and Tobin's $Q$ measured as $\left(v_{j t}-d_{j t}\right) / k_{j t}$ in Model 1 and $\left(v_{j t}-o_{j t}+b_{j t}\right) / k_{j t}$ in Model 2. Kaplan and Zingales classify firms on a scale from one to four on financial constraints, and perform an ordered logit of the scale onto the above characteristics. Lamont et al. then use these logit coefficients to construct an index of financial constraints, called the Kaplan-Zingales $(K Z)$ index, as:

$$
K Z_{j t}=-1.002 C F_{j t}+3.139 T L T D_{j t}-39.368 T D I V_{j t}-1.315 C A S H_{j t}+0.283 Q_{j t}
$$

Panel B of Table 5 reports Fama-MacBeth (1973) cross-sectional regressions of the multipliers onto contemporaneous firm characteristics motivated from Kaplan and Zingales (1997). Consistent with their evidence, our simulations show that firms are more constrained financially if they have lower cash flow relative to assets, higher debt relative to assets, lower ratios of dividends to assets, lower liquid assets or cash relative to total assets, and higher Tobin's $Q$. It is tempting to compare quantitatively the slopes from the models to those reported in Lamont, Polk, and Saá-Requejo (2001). However, doing so is inappropriate because the slopes in the data are from ordered logit regressions. We opt to use more precise OLS regressions in simulations because we can calculate precisely the multipliers using simulated data.

More interesting, armed with the effectively observable multipliers in model simulations, we can use Model 2 as a laboratory to evaluate the relative quality of the $K Z$ index and the $W W$ index as measures of financial constraints. Model 1 is unfit for this task because debt to assets and cash to assets are not defined in that model. Specifically, we perform Fama-MacBeth (1973) cross-sectional regressions of the multiplier, $\nu_{j t}$, onto the indexes, $K Z_{j t}$ and $W W_{j t}$, both separately and jointly. And we use the relative magnitudes of the slopes and the average cross-sectional $R^{2} \mathrm{~s}$ as measures of relative quality for the indexes. To make the magnitudes of their slopes comparable, we standardize both indexes by dividing their demeaned values with their respective standard deviations before using them in the cross-sectional regressions.

From Table 6 , both the $K Z$ index and the $W W$ index are positively correlated with the true 
multiplier. More important, the $W W$ index appears to do a much better job than the $K Z$ index as a proxy for the multiplier. From Panel A, in Model 2 with the benchmark parametrization, the average cross-sectional $R^{2}$ from regressing the multiplier onto the $W W$ index alone is $33.10 \%$, almost three times higher than the $R^{2}$ from using the $K Z$ index as the regressor, which is only $12.87 \%$. The slope of the $W W$ index in the joint regression with both indexes is 0.0576 , more than eight times of the magnitude for the $K Z$ slope, 0.0070. The two alternative parameterizations of Model 2 yield quantitatively similar, if not stronger, results. In the joint regression in Panel $\mathrm{C}$ with low fixed floatation costs, the slope of the $W W$ index is 0.15 with a significant $t$-statistic of 6.94 . In contrast, the slope of the $K Z$ index is now negative, -0.0161 , albeit insignificant. To sum up, the $K Z$ index largely looses its explanatory power for financial constraints in the presence of the $W W$ index.

Finally, there also exists some evidence on the cyclical properties of financial constraints. Using data on cross-sectional returns, Gomes, Yaron, and Zhang (2006) report that the shadow price of new equity is procyclical. In untabulated results, we find that the population, time-series correlations between the multiplier averaged across firms and aggregate productivity are 0.63 in Model 1, 0.60 in the benchmark parametrization of Model 2, and 0.59 and 0.69 in the high-liquidation-cost and low-fixed-floatation-cost cases of Model 2, respectively. These quantitative results are consistent with our earlier analysis based on Figures 2 and 6 . Replacing aggregate productivity by

aggregate investment-to-capital, measured as $\sum_{j=1}^{3000} i_{j t} / \sum_{j=1}^{3000} k_{j t}$ in simulations, lowers the corresponding correlations to $0.39,0.36,0.31$, and 0.31 , respectively. The correlations are lower because the aggregate investment-to-capital is an imperfect proxy for aggregate productivity. Our models thus provide a microfoundation for the interpretation in Gomes et al. that financial constraints are more binding when aggregate economic conditions are relatively good.

\section{Conclusion}

We construct two dynamic, neoclassical models to study the structural relations between financial constraints, stock returns, and business cycles. In Model 1, firms face dividend nonnegativity con- 
straints in a simple setting without debt or retained earnings. Model 2 is more realistic because firms can retained earnings, raise debt and equity, and face collateral constraints on debt capacity. The models predict that small firms, less profitable firms, and firms in debt are more likely to be financially constrained. These firms are also riskier and earn higher expected returns, although the effects of financial constraints on risk and expected returns can largely be subsumed quantitatively by market capitalization and book-to-market equity. Finally, because the stochastic discount factor makes capital investment more sensitive to aggregate shocks, financial constraints are more important when aggregate economic conditions are relatively good. 


\section{References}

Abel, Andrew B., and Janice C. Eberly, 1994, A unified model of investment under uncertainty, American Economic Review 84, 1369-1384.

Abel, Andrew B., and Janice C. Eberly, 1996, Optimal investment with costly reversibility, Review of Economic Studies 63, 581-593.

Almeida, Heitor, and Murillo Campello, 2005, Financial constraints, asset tangibility, and corporate investment, forthcoming, Review of Financial Studies.

Andrade, Gregor, and Steven N. Kaplan, 1998, How costly is financial (not economic) distress? Evidence from highly leveraged transactions that became distressed, Journal of Finance 53, 1443-1494.

Bansal, Ravi, and Amir Yaron, 2004, Risks for the long run: A potential resolution of asset pricing puzzles, Journal of Finance 59 (4), 1481-1509.

Barberis, Nicholas, Ming Huang, and Jesus Santos, 2001, Prospect theory and asset prices, Quarterly Journal of Economics 141 (1), 1-53.

Berk, Jonathan B., 1995, A critique of size related anomalies, Review of Financial Studies 8, $275-286$.

Berk, Jonathan B., Richard C. Green, and Vasant Naik, 1999, Optimal investment, growth options and security returns, Journal of Finance 54, 1153-1607.

Berk, Jonathan B., Richard C. Green, and Vasant Naik, 2004, Valuation and return dynamics of new ventures, Review of Financial Studies 17 (1), 1-35.

Bernanke, Ben and Mark Gertler, 1989, Agency costs, net worth, and business fluctuations, American Economic Review 79 (1), 14-31.

Bernanke, Ben, Mark Gertler, and Simon Gilchrist, 1999, The financial accelerator in a quantitative business cycle framework, in Handbook of Macroeconomics, Edited by Michael Woodford and John Taylor, North Holland.

Bond, Stephen and Costas Meghir, 1994, Dynamic investment models and the firm's financial policy, Review of Economic Studies 61, 197-222

Carlson, Murray, Adlai Fisher, and Ron Giammarino, 2004, Corporate investment and asset price dynamics: Implications for the cross section of returns, Journal of Finance 59 (6), 2577-2603.

Carlson, Murray, Adlai, Fisher, and Ron Giammarino, 2006, Corporate investment and asset price dynamics: Implications for SEO event studies and long-run performance, forthcoming, Journal of Finance

Carlstrom, Charles T., and Timothy S. Fuerst, 1997, Agency costs, net worth, and business fluctuations: A computable general equilibrium analysis, American Economic Review 87 (5), 893-910.

Campbell, John Y., and John H. Cochrane, 1999, By force of habit: A consumption-based explanation of aggregate stock market behavior, Journal of Political Economy 107, 205-251. 
Chan, K. C., and Nai-fu Chen, 1991, Structural and return characteristics of small and large firms, Journal of Finance 46, 1467-1484.

Christiano, Lawrence J., and Jonas D. M. Fisher, 2000, Algorithms for solving dynamic models with occasionally binding constraints, Journal of Economic Dynamics and Control 24, 11791232.

Cochrane, John H., 1991, Production-based asset pricing and the link between stock returns and economic fluctuations, Journal of Finance 46 (1), 209-237.

Cochrane, John H., 1996, A cross-sectional test of an investment-based asset pricing model, Journal of Political Economy 104, 572-621.

Cochrane, John H., 2001, Asset pricing, Princeton University Press.

Cooley, Thomas F., and Edward C. Prescott, 1995, Economic growth and business cycles, in Thomas F. Cooley, ed: Frontiers of Business Cycle Research (Princeton University Press, Princeton, NJ).

Cooley, Thomas F., and Vincenzo Quadrini, 2001, Financial markets and firm dynamics, American Economic Review 91 (5), 1286-1310.

Cooper, Ilan, 2006, Asset pricing implications of non-convex adjustment costs and irreversibility of investment, Journal of Finance 61 (1), 139-170.

Cooper, Russell, and João Ejarque, 2003, Financial frictions and investment: requiem in Q, Review of Economic Dynamics 6, 710-728.

Fama, Eugene F., and Kenneth R. French, 1992, The cross-section of expected stock returns, Journal of Finance XLVII, 427-465.

Fama, Eugene F., and Kenneth R. French, 1993, Common risk factors in the returns on stocks and bonds, Journal of Financial Economics 33, 3-56.

Fama, Eugene F., and Kenneth R. French, 1995, Size and book-to-market factors in earnings and returns, Journal of Finance 50, 131-155.

Fama, Eugene F., and James D. MacBeth, 1973, Risk return and equilibrium: Empirical tests, Journal of Political Economy 71, 607-636.

Fazzari, Stephen, R. Glenn Hubbard, and Bruce Peterson, 1988, Financing constraint and corporate investment, Brookings Papers on Economic Activity 1, 141-195.

Gala, Vito D., 2006, Investment and returns, working paper, University of Chicago.

Gertler, Mark, and Simon Gilchrist, 1994, Monetary policy, business cycles, and the behavior of small manufacturing firms, Quarterly Journal of Economics CIX (2), 309-340.

Gomes, Joao F., 2001, Financing investment, American Economic Review 90, 1263-1285.

Gomes, Joao F., Leonid Kogan, and Lu Zhang, 2003, Equilibrium cross section of returns, Journal of Political Economy 111, 693-732.

Gomes, Joao F., Amir Yaron, and Lu Zhang, 2003, Asset prices and business cycles with costly external finance, Review of Economic Dynamics 6 (4), 767-788. 
Gomes, Joao F., Amir Yaron, and Lu Zhang, 2006, Asset pricing implications of firms' financing constraints, forthcoming, Review of Financial Studies.

Graham, John R., 2000, How big are the tax benefits of debt? Journal of Finance 55, 1901-1941.

Hall, Robert E., 2001, The stock market and capital accumulation, American Economic Review 91, 1185-1202.

Hennessy, Christopher A., 2004, Tobin's Q, debt overhang, and investment, Journal of Finance LIX (4), 1717-1742.

Hennessy, Christopher A., Amnon Levy, and Toni M. Whited, 2005, Testing $Q$ theory of financing frictions, forthcoming, Journal of Financial Economics.

Hennessy, Christopher A., and Toni M. Whited, 2005, Debt dynamics, Journal of Finance 60 (3), 1129-1165.

Hennessy, Christopher A., and Toni M. Whited, 2006, How costly is external financing? Evidence from a structural estimation, forthcoming, Journal of Finance.

Judd, Kenneth L., 1998, Numerical methods in economics, the MIT press, Cambridge MA.

Kaplan, Steven N., and Luigi Zingales, 1997, Do investment-cash flow sensitivities provide useful measures of financing constraints? Quarterly Journal of Economics 112 (1), 169-215.

Kiyotaki, Nobuhiro, and John Moore, 1997, Credit cycles, Journal of Political Economy, 105 (2), 211-248.

Kogan, Leonid, 2004, Asset prices and real investment, Journal of Financial Economics 73, 411431.

Kothari, S. P., and Jay Shanken, 1997, Book-to-market, dividend yield, and expected market returns: A time-series analysis, Journal of Financial Economics 44, 169-203.

Kydland, Finn E., and Edward C. Prescott, 1982, Time to build and aggregate fluctuations, Econometrica 50, 1345-1370.

Lamont, Owen, Christopher Polk and Jesús Saá-Requejo, 2001, Financial constraints and stock returns, Review of Financial Studies 14 (2), 529-554.

Mas-Colell, Andreu, Michael D. Whinston, and Jerry R. Green, 1995, Microeconomy theory, Oxford University Press.

McGrattan, Ellen R., 1999, Application of weighted residual methods to dynamic economic models, in Ramon Marimon and Andrew Scott, eds.: Computational Methods for the Study of Dynamic Economies (Oxford University Press, Oxford).

Moyen, Nathalie, 2004, Investment-cash flow sensitivities: Constrained versus unconstrained firms, Journal of Finance 59 (5), 2061-2092.

Pástor, Luboš, and Pietro Veronesi, 2005, Rational IPO waves, Journal of Finance 60 (4), 17131757.

Perez-Quiros, Gabriel, and Allan Timmermann, 2000, Firm size and cyclical variations in stock returns, Journal of Finance 55, 1229-1262. 
Pontiff, Jeffrey, and Lawrence Schall, 1999, Book-to-market as a predictor of market returns, Journal of Financial Economics 49, 141-160.

Rajan, Raghuram G., and Luigi Zingales, 1995, What do we know about capital structure? Some evidence from international data, Journal of Finance 50 (5), 1421-1460.

Rouwenhorst, K. Geert, 1995, Asset pricing implications of equilibrium business cycle models, in Thomas Cooley, ed.: Frontiers of Business Cycle Research (Princeton University Press, Princeton, New Jersey).

Smith, Clifford W. Jr., 1977, Alternative methods for raising capital: rights versus underwritten offerings, Journal of Financial Economics 5 (3), 273-307.

Smith, Clifford W. Jr., and Ross L. Watts, 1992, The investment opportunity set and corporate financing, dividend, and compensation policies, Journal of Financial Economics 32, 263-292.

Stokey, Nancy L. and Robert E. Lucas, Jr. with Edward C. Prescott, 1989, Recursive methods in economic dynamics, Harvard University Press, Cambridge, Massachusetts.

Titman, Sheridan, and Roberto Wessels, 1988, The determinants of capital structure choice, Journal of Finance 43, 1-20.

Whited, Toni M., 1992, Debt, liquidity constraints, and corporate investment: Evidence from panel data, Journal of Finance, 47 (4), 1425-1460.

Whited, Toni M., and Guojun Wu, 2006, Financial constraints risk, Review of Financial Studies $19(2), 531-559$.

Zhang, Lu, 2005, The value premium, Journal of Finance 60 (1), 67-103. 


\section{A Derivations of the Lagrange Multipliers}

To derive equation (11), we combine the dividend nonnegativity constraint in equation (8) with the value function in equation (9). The resultant Lagrangian formulation of the value function, when evaluated at optimum, can be written as:

$$
v\left(k_{j t}, z_{j t}, x_{t}\right)=\left(1+\mu_{j t}\right) d\left(k_{j t}, i_{j t}, z_{j t}, x_{t}\right)+\mathrm{E}_{t}\left[m_{t+1} v\left(k_{j t+1}, z_{j t+1}, x_{t+1}\right)\right]
$$

Since $d\left(k_{j t}, i_{j t}, z_{j t}, x_{t}\right)$ is continuously differentiable with respect to $k_{j t}, v\left(k_{j t}, z_{j t}, x_{t}\right)$ is also differentiable with respect to $k_{j t}$ (see, for example, Theorem 9.10 in Stokey and Lucas with Prescott 1989). Equation (11) follows by differentiating both sides with respect to $k_{j t}$ and using the Envelope Theorem (see, for example, Theorem M.L.1 in Mas-Colell, Whinston, and Green 1995).

To characterize the multiplier given in equation (21) for Model 2, we first write down the infinite-horizon, Lagrangian formulation of the value function, denoted $\mathcal{L}$, as follows:

$$
\mathcal{L}_{j t}=\cdots+\pi\left(k_{j t}, z_{j t}, x_{t}\right)+\frac{b_{j t+1}}{\iota_{j t}}-\phi\left(i_{j t}, k_{j t}\right)-b_{j t}-\lambda\left(e_{j t}, k_{j t}\right)-\nu_{j t}\left(b_{j t+1}-s(1-\delta) k_{j t+1}\right)+
$$

$\mathrm{E}_{t}\left[m_{t+1}\left(\pi\left(k_{j t+1}, z_{j t+1}, x_{t+1}\right)+\frac{b_{j t+2}}{\iota_{j t+1}}-\phi\left(i_{j t+1}, k_{j t+1}\right)-b_{j t+1}-\lambda\left(e_{j t+1}, k_{j t+1}\right)-\nu_{j t+1}\left(b_{j t+2}-s(1-\delta) k_{j t+2}\right)+\cdots\right)\right]$

Note that $\mathcal{L}_{j t}$ is differentiable almost everywhere except when $\pi\left(k_{j t}, z_{j t}, x_{t}\right)+b_{j t+1} / \iota_{j t}-\phi\left(i_{j t}, k_{j t}\right)-$ $b_{j t}=0$. Thus, we can characterize $\nu_{j t}$ analytically only in the case when $e_{j t}$ is strictly positive.

When $e_{j t}>0$, differentiating $\mathcal{L}_{j t}$ with respect to $b_{j t+1}$ and recognizing

$$
e_{j t}=\phi\left(i_{j t}, k_{j t}\right)+b_{j t}-\pi\left(k_{j t}, z_{j t}, x_{t}\right)-\frac{b_{j t+1}}{\iota_{j t}}
$$

we obtain

$$
\frac{\partial \mathcal{L}_{j t}}{\partial b_{j t+1}}=\frac{1}{\iota_{j t}}+\frac{1}{\iota_{j t}} \lambda_{e}\left(e_{j t}, k_{j t}\right) \mathbf{1}_{j t}^{e}-\nu_{j t}-\mathrm{E}_{t}\left[m_{t+1}\left(1+\lambda_{e}\left(e_{j t+1}, k_{j t+1}\right) \mathbf{1}_{j t+1}^{e}\right)\right]=0
$$

Solving for $\nu_{j t}$ gives us:

$$
\nu_{j t}=\frac{1}{\iota_{j t}}\left[1+\lambda_{e}\left(e_{j t}, k_{j t}\right) \mathbf{1}_{j t}^{e}\right]-\mathrm{E}_{t}\left[m_{t+1}\left(1+\lambda_{e}\left(e_{j t+1}, k_{j t+1}\right) \mathbf{1}_{j t+1}^{e}\right)\right]
$$

We can simplify equation (A1) further by noting that the collateral constraint binds $\left(\nu_{j t}>0\right)$ when $b_{j t+1}>0$ and $\iota_{j t}=r_{f t}=1 / \mathrm{E}_{t}\left[m_{t+1}\right]$. Equation (A1) then becomes:

$$
\nu_{j t}=\frac{1}{r_{f t}} \lambda_{e}\left(e_{j t}, k_{j t}\right) \mathbf{1}_{j t}^{e}-\mathrm{E}_{t}\left[m_{t+1} \lambda_{e}\left(e_{j t+1}, k_{j t+1}\right) \mathbf{1}_{j t+1}^{e}\right]
$$

\section{B Computation}

We use the discrete-state value function iteration technique to solve the dynamic valuemaximization problems of firms in both Models 1 and 2. Piecewise linear interpolation is used extensively to obtain firm value and policy functions which do not lie directly on the grid points. The Matlab programs used to solve the dynamic programming problems and the $\mathrm{C}++$ programs used to simulate the models in this paper are available upon request. 


\section{B.1 Model 1: Dividend Nonnegativity Constraints}

For Model 1, the value function and the optimal investment policy are solved on a grid in a discrete state space. We specify a grid with 50 points for the capital stock with an upper bound $\bar{k}$ (large enough to be nonbinding at all times). Following McGrattan (1999), we construct the grid for capital stock recursively, i.e., $k_{i}=k_{i-1}+c_{k 1} \exp \left(c_{k 2}(i-2)\right)$, where $i=1, \ldots, 50$ is the index of grid points, and $c_{k 1}$ and $c_{k 2}$ are two constants chosen to provide the desired number of grid points and $\bar{k}$, given a pre-specified lower bound $\underline{k}$. The advantage of this recursive construction is that more grid points are assigned around $\underline{k}$, where the value function has most of its curvature.

The state variables $x$ and $z$ are defined on continuous state spaces that can be transformed into discrete state spaces using the Rouwenhorst (1995) methods. We use three grid points for the $x$ process and five points for the $z$ process. In all cases our results are robust to finer grids. Once the discrete state space is available, the conditional expectation operator can be carried out as a matrix multiplication. The expected return $\mathrm{E}_{t}\left[r_{j t+1}\right]=\mathrm{E}_{t}\left[v_{j t+1}\right] /\left(v_{j t}-d_{j t}\right)$ can be calculated in a similar way. Piecewise linear interpolation is used extensively to obtain firm value, optimal investment, and expected return, which do not lie directly on the grid points. Finally, to solve for the Lagrange multiplier on the grid according to equation (11), we use numerical differentiation to calculate the first order derivative $v_{k}$ with quadratic accuracy (e.g., Judd 1998, p.281). $d_{k}$ can be calculated analytically.

\section{B.2 Model 2: Collateral Constraints}

Model 2 is substantially more challenging to solve than Model 1.

The capital stock in each period is constrained to be an element of the linear finite time-invariant set $\mathcal{K}=\left\{k_{1}, \ldots, k_{N_{K}}\right\}$, with total of $N_{K}=50$ elements (grid points). For any optimal capital stock on the grid, the finer grid used for the interpolation consists of 1000 evenly spaced points. The face value of one-period debt, $b$, in each period is constrained to be an element of the linear finite time-invariant set $\mathcal{B}=\left\{b_{1}, \ldots, b_{N_{B}}\right\}$, centered around zero with total of $N_{B}=2 N_{K}+1=101$ elements (grid points). The boundaries of the set, $\left\{b_{1}, b_{N_{B}}\right\}$ are the same for any $k_{i} \in \mathcal{K}$ are chosen to satisfy a weaker form of the collateral constraints:

$$
\left\{b_{1}, b_{N_{B}}\right\}= \pm s(1-\delta) k_{N_{K}}
$$

For any optimal debt on the grid chosen from a first-pass optimization, the finer grid used for the interpolation consists of 1001 evenly spaced points. The state variables $x \in \mathcal{X}$ and $z \in \mathcal{Z}$ are defined on continuous state spaces. We again transform the state spaces into discrete ones using the Rouwenhorst (1995) methods. We use nine points for the $z$ process and five points for the $x$ process.

We can formulate the dynamic value-maximization problem on the grid as follows:

$$
\begin{gathered}
v^{n}\left(k_{i}, b_{j}, z_{l}, x_{m}\right)=\max _{\left\{k^{\prime}, b^{\prime}\right\} \in \mathcal{K}^{\prime} \times \mathcal{B}^{\prime}}\left\{\pi\left(k_{i}, z_{l}, x_{m}\right)+\frac{b^{\prime}}{\iota\left(x_{m}\right)}-b_{j}-\phi\left(k^{\prime}, k_{i}\right)-\lambda\left(e\left(k_{i}, b_{j}, z_{l}, x_{m}, k^{\prime}, b^{\prime}\right), k_{j}\right)+\right. \\
+\sum_{l=1}^{9} \sum_{m=1}^{5} \eta e^{\left(\gamma_{0}+\gamma_{1}\left(x_{m}-\bar{x}\right)\right)\left(x_{m}-x^{\prime}\right)} \widetilde{v}^{n-1}\left(k^{\prime}, b^{\prime}, z_{l^{\prime}}, x_{m^{\prime}}\right) Q_{z}\left(z_{l^{\prime}} \mid z_{l}\right) Q_{x}\left(x_{m^{\prime}} \mid x_{m}\right)
\end{gathered}
$$

where $\widetilde{v}$ incorporates the collateral constraint as follows:

$$
\widetilde{v}^{n}=v^{n} \mathbf{1}_{\left\{b^{\prime} \leq s(1-\delta) k^{\prime}\right\}}-10^{10}\left(1-\mathbf{1}_{\left\{b^{\prime} \leq s(1-\delta) k^{\prime}\right\}}\right)
$$


and $n$ indicates the number of value iterations. $v^{n}: \mathcal{K} \times \mathcal{B} \times \mathcal{X} \times \mathcal{Z}$ is a list of 227,250 values as compared to 8,250 values used for Model 1.

The algorithm can be described as follows:

- Make a guess for $v^{n-1}(k, b, z, x)$ on the right hand side of (A3). It will be an $25 \times 51 \times 9 \times 5$ object.

- For each $\{k, b, z, x\} \in \mathcal{K} \times \mathcal{B} \times \mathcal{X} \times \mathcal{Z}$ point use local linear interpolation to construct $v^{n-1}\left(k^{\prime}, b^{\prime}, z, x\right)$. In Matlab, reshape the $v^{n-1}$ into a traditional $\mathcal{K} \times \mathcal{B}$ matrix and again reshape after the interpolation to form a three-dimensional object $v^{n-1}\left(k^{\prime}, b^{\prime}, z, x\right)$. Since $\mathcal{K} \times \mathcal{B}$ is not a square matrix, it requires to perform interpolation along each dimension separately. The order is not important.

- On the $\mathcal{K}^{\prime} \times \mathcal{B}^{\prime}$ grid construct $\mathbf{1}_{\left\{b^{\prime} \leq s(1-\delta) k^{\prime}\right\}}$ which is a three-dimensional object of zeros and ones and use it to construct $\widetilde{v}^{n-1}\left(k^{\prime}, b^{\prime}, z, x\right)$.

- For each $\{k, b, z, x\} \in \mathcal{K} \times \mathcal{B} \times \mathcal{X} \times \mathcal{Z}$ solve for optimal $\left\{k^{*}(k, b, z, x), b^{*}(k, b, z, x)\right\} \in \mathcal{K}^{\prime} \times \mathcal{B}^{\prime}$ from

$$
\begin{aligned}
\left\{k^{\prime}(k, b, z, x), b^{\prime}\right. & (k, b, z, x)\}=\underset{\left\{k^{\prime}, b^{\prime}\right\} \in \mathcal{K}^{\prime} \times \mathcal{B}^{\prime}}{\arg \max }\left\{\frac{b^{\prime}}{\iota\left(x_{m}\right)}-\phi\left(k^{\prime}, k_{i}\right)-\lambda\left(e\left(k_{i}, b_{j}, z_{l}, x_{m}, k^{\prime}, b^{\prime}\right), k_{j}\right)+\right. \\
& \left.+\sum_{l=1}^{9} \sum_{m=1}^{5} \eta e^{\left(\gamma_{0}+\gamma_{1}\left(x_{m}-\bar{x}\right)\right)\left(x_{m}-x^{\prime}\right)} Q_{z}\left(z_{l^{\prime}} \mid z_{l}\right) Q_{x}\left(x_{m^{\prime}} \mid x_{m}\right) \widetilde{v}^{n-1}\left(k^{\prime}, b^{\prime}, z_{l^{\prime}}, x_{m^{\prime}}\right)\right\}
\end{aligned}
$$

by doing a simple grid search along $k^{\prime}$ holding $b^{\prime}$ fixed and then along $b^{\prime}$ for each $k^{*}$.

- Construct $v^{n}(k, b, z, x)$ from equation (A3).

- Check for conversion using maximum error algorithm

$$
\max \left|v^{n}(k, b, z, x)-v^{n-1}(k, b, z, x)\right|<\epsilon=10^{-5} .
$$

- If the conversion criteria is not satisfied set $v^{n}(k, b, z, x)$ as a new guess and repeat all of the above steps. 


\section{Table 1: Benchmark Parameter Values}

This table lists the benchmark parameter values used to solve and simulate Model 1 with the dividend nonnegativity constraints and Model 2 with the collateral constraints. Panel A reports the parameters common to both models, and Panel B reports the parameters specific to Model 2.

\begin{tabular}{ccl}
\hline Notation & Parameter Value & Description \\
\hline & Panel A: Parameters Common to Both Models 1 and 2 \\
\hline$\alpha$ & 0.30 & Capital share in production \\
$\delta$ & 0.01 & Monthly rate of capital depreciation \\
$\rho_{x}$ & $0.95^{1 / 3}$ & Persistence coefficient of aggregate productivity \\
$\sigma_{x}$ & $0.007 / 3$ & Conditional volatility of aggregate productivity \\
$\eta$ & 0.994 & Time-preference coefficient \\
$\gamma_{0}$ & 50 & Constant price of risk parameter \\
$\gamma_{1}$ & -1000 & Time-varying price of risk parameter \\
$a_{P}$ & 15 & Adjustment-cost parameter when investment is positive \\
$a_{N}$ & 150 & Adjustment-cost parameter when investment is negative \\
$\rho_{z}$ & 0.96 & Persistence coefficient of firm-specific productivity \\
$\sigma_{z}$ & 0.10 & Conditional volatility of firm-specific productivity \\
$f$ & 0.0275 & Fixed cost of production \\
\hline & \multicolumn{2}{c}{ Panel B: Parameters Specific to Model 2 } \\
\hline$\lambda_{0}$ & 0.85 & Liquation value per unit of capital net of bankruptcy cost \\
$\lambda_{1}$ & 0.08 & Fixed floatation cost parameter \\
& 0.025 & Proportional floatation cost parameter \\
& $0.50 \% / 12$ & Monthly wedge between the borrowing and saving rates of interest
\end{tabular}


Table 2 : Monthly Stock Returns of Portfolios Based on One-Way Sorts on the Multiplier in Model Simulations

This table reports descriptive statistics for ten value-weighted and ten equal-weighted portfolios from one-way sorts on the Lagrange multiplier from Models 1 and 2. We report average returns in percent per month for each portfolio as well as the average high-minus-low portfolios and its $t$-statistics. We sort all firms based on their Lagrange multipliers at the beginning of each year and then hold the portfolios for the whole year. For each model, we simulate 100 artificial panels, each of which has 3000 firms and 480 monthly observations, and we then report the across-simulation averaged results. Panel A reports the quantitative results from Model 1, in which all firms face the dividend nonnegativity constraints without corporate saving and borrowing. Panel B reports the results from Model 2 , in which all firms can save but face the collateral constraints on borrowing. And Panel B reports the simulation results from Model 2 using the benchmark parameters reported in Table 1. Panel C reports the simulation results from Model 2 using the benchmark parameters except that the liquidation value per unit of capital net of liquidation costs, $s$, is set to be 0.70. Finally, Panel D reports the simulation results from Model 2 using the benchmark parameters except that the fixed cost of equity financing, $\lambda_{0}$, is set to be 0.02 .

\begin{tabular}{|c|c|c|c|c|c|c|c|c|c|c|c|c|}
\hline & Low & 2 & 3 & 4 & 5 & 6 & 7 & 8 & 9 & High & $\mathrm{FC}$ & $t_{\mathrm{FC}}$ \\
\hline & \multicolumn{10}{|c|}{ Panel A: Model 1} & & \\
\hline Value-weighted & 0.65 & 0.68 & 0.72 & 0.74 & 0.79 & 0.83 & 0.85 & 0.87 & 0.98 & 1.24 & 0.59 & $(5.11)$ \\
\hline \multirow[t]{2}{*}{ Equally-weighted } & 0.61 & 0.63 & 0.67 & 0.70 & 0.73 & 0.79 & 0.80 & 0.82 & 0.93 & 1.18 & 0.57 & $(5.13)$ \\
\hline & \multicolumn{10}{|c|}{ Panel B: Model 2 (the Benchmark Parametrization) } & & \\
\hline Value-weighted & 0.54 & 0.61 & 0.64 & 0.67 & 0.68 & 0.70 & 0.74 & 0.76 & 0.78 & 0.84 & 0.30 & $(4.42)$ \\
\hline \multirow[t]{2}{*}{ Equally-weighted } & 0.42 & 0.49 & 0.52 & 0.55 & 0.56 & 0.59 & 0.62 & 0.65 & 0.67 & 0.73 & 0.31 & $(3.76)$ \\
\hline & \multicolumn{10}{|c|}{ Panel C: Model 2 (High Liquidation Cost, $s=0.70)$} & & \\
\hline Value-weighted & 0.33 & 0.37 & 0.39 & 0.44 & 0.48 & 0.49 & 0.55 & 0.57 & 0.60 & 0.71 & 0.38 & $(4.87)$ \\
\hline \multirow[t]{2}{*}{ Equally-weighted } & 0.27 & 0.31 & 0.33 & 0.37 & 0.39 & 0.39 & 0.44 & 0.47 & 0.51 & 0.62 & 0.35 & $(4.08)$ \\
\hline & \multicolumn{10}{|c|}{ Panel D: Model 2 (Low Floatation Cost, $\lambda_{0}=0.02$ ) } & & \\
\hline Value-weighted & 0.50 & 0.60 & 0.64 & 0.71 & 0.74 & 0.74 & 0.79 & 0.83 & 0.89 & 1.03 & 0.53 & $(5.44)$ \\
\hline Equally-weighted & 0.38 & 0.47 & 0.52 & 0.59 & 0.62 & 0.62 & 0.68 & 0.71 & 0.77 & 0.91 & 0.53 & $(4.87)$ \\
\hline
\end{tabular}


Table 3 : Average Monthly Percentage Returns for Portfolios Sorted on the Multiplier and Market Capitalization in Model Simulations

This table reports average returns in monthly percent for nine value-weighted portfolios sorted on the market capitalization and the Lagrange multiplier in model simulations. The rankings are performed annually and independently such that each portfolio contains firms both in a given size category and a given financial constraints category. Following Lamont, Polk, and Saá-Requejo (2001) and Whited and Wu (2006), we define small-cap firms (S) as firms that are in the bottom $40 \%$ of the sample sorted on market capitalization, mid-cap firms (M) are firms in the middle $20 \%$ of the sample, and large-cap firms (B) are firms in the top $40 \%$ of the sample. Similarly, low-, middle-, and high-multiplier are firms in the bottom $40 \%$ (L), the middle $20 \%$ (M), and the top $40 \%$ (H) of the sample sorted on the multiplier, respectively. We also define the average high-FC portfolio as HIGHFC $=(\mathrm{BH}+\mathrm{MH}+\mathrm{SH}) / 3$, and the average low-FC portfolio as LOWFC $=$ $(\mathrm{BL}+\mathrm{ML}+\mathrm{SL}) / 3$, and the financial constraints factor as FC $=$ HIGHFC - LOWFC. For each model, we simulate 100 artificial panels, each of which has 3000 firms and 480 monthly observations, and we then report the across-simulation averaged results. The third column reports the quantitative results from Model 1 , in which all firms face the dividend nonnegativity constraints. The fourth column reports the results from Model 2 , in which all firms can save but face the collateral constraints on borrowing. This column reports the simulation results from Model 2 using the benchmark parameters reported in Table 1. The fifth column reports the simulation results from Model 2 using the benchmark parameters except that the liquidation value per unit of capital net of liquidation costs, $s$, is set to be 0.70 . And the sixth column reports the simulation results from Model 2 using the benchmark parameters except that the fixed floatation cost of equity, $\lambda_{0}$, is set to be 0.02 . The last two columns report those from Table I of Lamont et al. and from Table 4 of Whited and Wu (2006).

\begin{tabular}{|c|c|c|c|c|c|c|c|}
\hline & Category & Model 1 & $\begin{array}{c}\text { Model } 2 \\
\text { (Benchmark) } \\
\end{array}$ & $\begin{array}{c}\text { Model } 2 \\
(s=0.70) \\
\end{array}$ & $\begin{array}{c}\text { Model 2 } \\
\left(\lambda_{0}=0.02\right) \\
\end{array}$ & $\begin{array}{c}\text { Lamont et al. } \\
(2001)\end{array}$ & $\begin{array}{c}\text { Whited and Wu } \\
(2005)\end{array}$ \\
\hline \multicolumn{8}{|l|}{ Small-cap firms } \\
\hline Low FC & $\mathrm{SL}$ & 1.32 & 0.81 & 0.12 & 0.86 & 0.45 & 0.89 \\
\hline Middle FC & SM & 1.62 & 0.85 & 0.32 & 0.95 & 0.67 & 0.66 \\
\hline High FC & $\mathrm{SH}$ & 2.40 & 0.91 & 0.55 & 1.05 & 0.38 & 0.83 \\
\hline \multicolumn{8}{|l|}{ Mid-cap firms } \\
\hline Low FC & ML & 1.03 & 0.69 & 0.07 & 0.70 & 0.37 & 0.65 \\
\hline Middle FC & MM & 1.27 & 0.70 & 0.19 & 0.73 & 0.56 & 0.81 \\
\hline High FC & $\mathrm{MH}$ & 0.97 & 0.72 & 0.09 & 0.79 & 0.26 & 0.74 \\
\hline \multicolumn{8}{|l|}{ Large-cap firms } \\
\hline Low FC & $\mathrm{BL}$ & 0.86 & 0.35 & 0.04 & 0.50 & 0.47 & 0.71 \\
\hline Middle FC & $\mathrm{BM}$ & 0.89 & 0.56 & 0.06 & 0.56 & 0.53 & 0.96 \\
\hline High FC & $\mathrm{BH}$ & 1.11 & 0.79 & 0.10 & 0.63 & 0.25 & 1.23 \\
\hline HIGHFC & & 1.49 & 0.81 & 0.25 & 0.82 & 0.30 & 0.93 \\
\hline LOWFC & & 1.07 & 0.62 & 0.08 & 0.69 & 0.43 & 0.75 \\
\hline $\begin{array}{l}\mathrm{FC} \\
t \text {-statistics of FC }\end{array}$ & & $\begin{array}{c}0.42 \\
(2.05) \\
\end{array}$ & $\begin{array}{c}0.19 \\
(0.76) \\
\end{array}$ & $\begin{array}{c}0.17 \\
(0.81) \\
\end{array}$ & $\begin{array}{c}0.13 \\
(0.50) \\
\end{array}$ & $\begin{array}{l}-0.13 \\
(-1.17) \\
\end{array}$ & $\begin{array}{c}0.18 \\
(0.95) \\
\end{array}$ \\
\hline
\end{tabular}




\section{Table 4 : Fama-MacBeth (1973) Monthly Cross-Sectional Regressions of Percentage Stock Returns onto Lagrange Multiplier,}

Size, and Book-to-Market in Model Simulations

This table reports the Fama-MacBeth (1973) monthly cross-sectional regressions of stock returns, $r_{j t+1}$, onto the Lagrange multiplier, size, and book-to-market, all measured at the beginning of month $t . \mu_{j t}$ denotes the multiplier in Model 1, and $\nu_{j t}$ denotes the multiplier in Model 2 . $\ln (\mathrm{ME})$ is the logarithm of the total market value of equity, measured as $\ln \left(v_{j t}-d_{j t}\right)$ in Model 1 and $\ln \left(v_{j t}-o_{j t}\right)$ in Model $2 . \ln (\mathrm{BE} / \mathrm{ME})$ is the logarithm of the book-to-market equity ratio, measured as $\ln \left(k_{j t} /\left(v_{j t}-d_{j t}\right)\right)$ in Model 1 and $\ln \left(\left(k_{j t}-b_{j t}\right) /\left(v_{j t}-o_{j t}\right)\right)$ in Model 2. For each model, we simulate 100 artificial panels, each of which has 3000 firms and 480 monthly observations, and then report the across-simulation averaged Fama-MacBeth slopes and $t$-statistics. Panel A reports the quantitative results from Model 1, in which all firms face the dividend nonnegativity constraints without corporate saving and borrowing. Panel B reports the results from Model 2, in which all firms can save but face the collateral constraints on borrowing. Panel B reports the simulation results from Model 2 using the benchmark parameters reported in Table 1. Panel C reports the simulation results from Model 2 using the benchmark parameters except that the liquidation value per unit of capital net of liquidation costs, $s$, is set to be 0.70 . Finally, Panel D reports the simulation results from Model 2 using the benchmark parameters except that the fixed floatation cost, $\lambda_{0}$, is set to be 0.02 .

\begin{tabular}{|c|c|c|c|c|c|}
\hline \multicolumn{3}{|c|}{ Panel A: Model 1} & \multicolumn{3}{|c|}{ Panel B: Model 2 (The Benchmark Parametrization) } \\
\hline$\mu_{j t}$ & $\ln (\mathrm{ME})$ & $\ln (\mathrm{BE} / \mathrm{ME})$ & $\nu_{j t}$ & $\ln (\mathrm{ME})$ & $\ln (\mathrm{BE} / \mathrm{ME})$ \\
\hline $\begin{array}{c}1.39 \\
(2.98)\end{array}$ & & & $\begin{array}{c}6.23 \\
(2.79)\end{array}$ & & \\
\hline $\begin{array}{c}0.99 \\
(1.81) \\
\end{array}$ & $\begin{array}{l}-15.93 \\
(-2.46)\end{array}$ & $\begin{array}{l}12.78 \\
(2.53) \\
\end{array}$ & $\begin{array}{c}2.60 \\
(0.65) \\
\end{array}$ & $\begin{array}{c}-2.99 \\
(-2.51) \\
\end{array}$ & $\begin{array}{c}0.42 \\
(2.60) \\
\end{array}$ \\
\hline \multicolumn{3}{|c|}{ Panel C: Model 2 (High Liquidation Cost, $s=0.70$ ) } & \multicolumn{3}{|c|}{ Panel D: Model 2 (Low Fixed Floatation Cost, $\lambda_{0}=0.02$ ) } \\
\hline$\nu_{j t}$ & $\ln (\mathrm{ME})$ & $\ln (\mathrm{BM})$ & $\nu_{j t}$ & $\ln (\mathrm{ME})$ & $\ln (\mathrm{BM})$ \\
\hline $\begin{array}{c}2.56 \\
(2.83)\end{array}$ & & & $\begin{array}{c}5.15 \\
(3.22)\end{array}$ & & \\
\hline $\begin{array}{c}1.20 \\
(1.16)\end{array}$ & $\begin{array}{c}-1.54 \\
(-2.21)\end{array}$ & $\begin{array}{c}0.76 \\
(1.92)\end{array}$ & $\begin{array}{c}-0.11 \\
(-0.14)\end{array}$ & $\begin{array}{l}-3.10 \\
(-2.36)\end{array}$ & $\begin{array}{c}0.24 \\
(1.61)\end{array}$ \\
\hline
\end{tabular}


Table 5 : Cross-Sectional Determinants of the Lagrange Multipliers in Model Simulations

This table reports Fama-MacBeth (1973) monthly cross-sectional regressions of the multipliers. Panel A reports the regression similar to that reported in column 4 of Table I in Whited and Wu (2006): $\mu_{j t}\left(\right.$ or $\left.\nu_{j t}\right)=b_{0}+b_{1} C F_{j t}+b_{2} T L T D_{j t}+b_{3} L N T A_{j t}+b_{4} S G_{j t}+b_{5} D I V P O S_{j t}+\epsilon_{j t}$, where $\mu_{j t}$ is the multiplier in Model (Mod) 1 and $\nu_{j t}$ is the multiplier in Model 2 for firm $j$ during month $t$. $C F_{j t}$ is the cash flow-to-asset ratio, TLTD $D_{j t}$ is the total debt-to-assets ratio, $L N T A_{j t}$ is the logarithm of the total assets, $S G_{j t}$ is the firm-level sales growth, and $D I V P O S_{j t}$ is a dummy variable that equals one if firm $j$ has paid dividends during month $t$, and equals zero otherwise. Panel B reports the regression similar to that reported in Table 9 in Lamont, Polk, and Saá-Requejo (2001), the regression which is in turn based on Kaplan and Zingales (1997): $\mu_{j t}$ (or $\left.\nu_{j t}\right)=b_{0}+b_{1} C F_{j t}+b_{2} T L T D_{j t}+b_{3} T D I V_{j t}+b_{4} C A S H_{j t}+b_{5} Q_{j t}+\epsilon_{j t}$, where $C F_{j t}$ is the cash flow-to-asset ratio, $T L T D_{j t}$ is the total debt-to-assets ratio, $T D I V_{j t}$ is the dividend-to-assets ratio, $C A S H_{j t}$ is the ratio of total amount of liquid assets or cash divided by assets, and $Q_{j t}$ is Tobin's $Q$. The $t$-statistics are shown in parentheses. We report quantitative results for Model 1 , in which all firms face the dividend nonnegativity constraints, and three parameterizations of Model 2, in which all firms can save but face the collateral constraints on borrowing. These three cases include the benchmark parametrization reported in Table 1; the high-liquidation-cost case with the liquidation value per unit of capital net of liquidation costs, $s$, being 0.70; and the low fixed-floatation-cost case with the fixed floatation cost of equity, $\lambda_{0}$, being 0.02 . For each case, we simulate 100 artificial panels, each of which has 3000 firms and 480 months, and we then report the across-simulation averaged results. We also compare our simulated results to those from Lamont et al. and Whited and Wu (reported in the "Data" column).

\begin{tabular}{|c|c|c|c|c|c|c|c|c|c|c|c|c|c|c|}
\hline \multicolumn{3}{|c|}{ Cash Flow/Assets, $C F$} & \multicolumn{3}{|c|}{ Total Debt/Assets, TLTD } & \multicolumn{3}{|c|}{$\log ($ Sales $), L N T A$} & \multicolumn{3}{|c|}{ Sales Growth, $S G$} & \multicolumn{3}{|c|}{ Dividend Dummy, DIVPOS } \\
\hline Data & Mod 1 & Mod 2 & Data & Mod 1 & Mod 2 & Data & Mod 1 & Mod 2 & Data & Mod 1 & Mod 2 & Data & Mod 1 & Mod 2 \\
\hline $\begin{array}{c}-0.09 \\
(-2.94)\end{array}$ & $\begin{array}{c}-0.13 \\
(-8.77)\end{array}$ & $\begin{array}{c}-0.14 \\
(-8.02)\end{array}$ & $\begin{array}{c}0.02 \\
(1.91)\end{array}$ & $\begin{array}{l}- \\
-\end{array}$ & $\begin{array}{c}0.01 \\
(3.66)\end{array}$ & $\begin{array}{l}-0.04 \\
(-1.91)\end{array}$ & $\begin{array}{c}-0.15 \\
(-8.89)\end{array}$ & $\begin{array}{c}-0.03 \\
(-7.39)\end{array}$ & $\begin{array}{c}-0.04 \\
(-1.52)\end{array}$ & $\begin{array}{c}-0.18 \\
(-5.28)\end{array}$ & $\begin{array}{c}-0.00 \\
(-2.15)\end{array}$ & $\begin{array}{c}-0.06 \\
(-2.14)\end{array}$ & $\begin{array}{c}-0.00 \\
(-1.73)\end{array}$ & $\begin{array}{c}-0.05 \\
(-2.69)\end{array}$ \\
\hline \multirow[t]{2}{*}{ Mod 2} & $(s=0.70)$ & $\left(\lambda_{0}=0.02\right)$ & Mod 2 & $(s=0.70)$ & $\left(\lambda_{0}=0.02\right)$ & Mod 2 & $(s=0.70)$ & $\left(\lambda_{0}=0.02\right)$ & Mod 2 & $(s=0.70)$ & $\left(\lambda_{0}=0.02\right)$ & Mod 2 & $(s=0.70)$ & $\left(\lambda_{0}=0.02\right)$ \\
\hline & $\begin{array}{c}-0.02 \\
(-4.17) \\
\end{array}$ & $\begin{array}{c}-0.20 \\
(-3.91) \\
\end{array}$ & & $\begin{array}{c}0.03 \\
(3.84) \\
\end{array}$ & $\begin{array}{c}0.03 \\
(2.40) \\
\end{array}$ & & $\begin{array}{c}-0.03 \\
(-6.11) \\
\end{array}$ & $\begin{array}{c}-0.03 \\
(-3.20) \\
\end{array}$ & & $\begin{array}{c}-0.00 \\
(-3.58) \\
\end{array}$ & $\begin{array}{c}-0.00 \\
(-2.05) \\
\end{array}$ & & $\begin{array}{c}-0.02 \\
(-2.10) \\
\end{array}$ & .09 \\
\hline \multicolumn{15}{|c|}{ Panel B: $\mu_{j t}\left(\right.$ or $\left.\nu_{j t}\right)=b_{0}+b_{1} C F_{j t}+b_{2} T L T D_{j t}+b_{3} T D I V_{j t}+b_{4} C A S H_{j t}+b_{5} Q_{j t}+\epsilon_{j t}$, motivated from Kaplan and Zingales $(1997)$} \\
\hline \multicolumn{3}{|c|}{ Cash Flow/Assets, $C F$} & \multicolumn{3}{|c|}{ Total Debt/Assets, TLTD } & \multicolumn{3}{|c|}{ Dividends/Assets, $T D I V$} & \multicolumn{3}{|c|}{ Cash/Assets, $C A S H$} & \multicolumn{3}{|c|}{ Tobin's $Q, Q$} \\
\hline Data & Mod 1 & Mod 2 & Data & Mod 1 & Mod 2 & Data & Mod 1 & Mod 2 & Data & Mod 1 & Mod 2 & Data & Mod 1 & Mod 2 \\
\hline $\begin{array}{c}-1.00 \\
(-4.28)\end{array}$ & $\begin{array}{c}-2.88 \\
(-6.66)\end{array}$ & $\begin{array}{c}-1.06 \\
(-4.67)\end{array}$ & $\begin{array}{c}3.14 \\
(6.99)\end{array}$ & $\begin{array}{l}- \\
-\end{array}$ & $\begin{array}{c}1.78 \\
(3.79)\end{array}$ & $\begin{array}{l}-39.37 \\
(-6.46)\end{array}$ & $\begin{array}{l}-17.34 \\
(-6.91)\end{array}$ & $\begin{array}{c}-6.28 \\
(-8.99)\end{array}$ & $\begin{array}{c}-1.32 \\
(-4.55)\end{array}$ & $\begin{array}{l}- \\
-\end{array}$ & $\begin{array}{c}-0.86 \\
(-2.11)\end{array}$ & $\begin{array}{c}0.28 \\
(3.63)\end{array}$ & $\begin{array}{l}1.27 \\
(6.04)\end{array}$ & $\begin{array}{c}0.37 \\
(5.28)\end{array}$ \\
\hline Mod 2 & $(s=0.70)$ & $\left(\lambda_{0}=0.02\right)$ & Mod 2 & $(s=0.70)$ & $\left(\lambda_{0}=0.02\right)$ & Mod 2 & $(s=0.70)$ & $\left(\lambda_{0}=0.02\right)$ & Mod 2 & $(s=0.70)$ & $\left(\lambda_{0}=0.02\right)$ & Mod 2 & $(s=0.70)$ & $\left(\lambda_{0}=0.02\right)$ \\
\hline & $\begin{array}{c}-0.73 \\
(-4.61) \\
\end{array}$ & $\begin{array}{c}-2.22 \\
(-6.75) \\
\end{array}$ & & $\begin{array}{c}1.84 \\
(7.36) \\
\end{array}$ & $\begin{array}{c}0.93 \\
(3.38) \\
\end{array}$ & & $\begin{array}{c}-6.33 \\
(-5.10) \\
\end{array}$ & $\begin{array}{c}-6.49 \\
(-8.64) \\
\end{array}$ & & $\begin{array}{c}-1.01 \\
(-5.68) \\
\end{array}$ & $\begin{array}{c}-0.56 \\
(-3.05) \\
\end{array}$ & & $\begin{array}{c}0.77 \\
(6.20) \\
\end{array}$ & $\begin{array}{c}0.52 \\
(5.92) \\
\end{array}$ \\
\hline
\end{tabular}


Table 6 : Fama-MacBeth (1973) Cross-Sectional Regressions of the Lagrange Multiplier onto the Kaplan and Zingales (1997) Index and the Whited and Wu (2006) Index of Financial Constraints, Model 2 with the Collateral Constraints

Using simulated panels from Model 2 with collateral constraints, this table reports the Fama-MacBeth (1973) monthly cross-sectional regressions of the Lagrange multiplier, $\nu_{j t}$, onto the Kaplan and Zingles $(1997, K Z)$ index and the Whited and $\mathrm{Wu}(2006, W W)$ index of financial constraints, both separately and jointly. We simulate 100 artificial panels, each of which has 3000 firms and 480 monthly observations, and then report the across-simulation averaged Fama-MacBeth slopes, heteroscedasticity and autocorrelation-consistent $t$-statistics (in parentheses), and average cross-sectional $R^{2}$ s. We also report the average cross-sectional correlation between the $K Z$ index and the $W W$ index. Panel A reports the quantitative results from the benchmark parametrization of Model 2 with the parameter values in Table 1. Panel B reports the results from Model 2 using the benchmark parameters except that the liquidation value per unit of capital net of liquidation costs, $s$, is set to be 0.70 . Finally, Panel $\mathrm{C}$ reports the results from Model 2 using the benchmark parameters except that the fixed floatation cost, $\lambda_{0}$, is set to be 0.02 .

\begin{tabular}{|c|c|c|c|c|c|c|c|}
\hline \multicolumn{8}{|c|}{ Panel A: Model 2 (the Benchmark Case) } \\
\hline$K Z$ & $R^{2}$ & $W W$ & $R^{2}$ & $K Z$ & $W W$ & $R^{2}$ & $\operatorname{Corr}(K Z, W W)$ \\
\hline $\begin{array}{l}0.0269 \\
(13.13)\end{array}$ & $12.87 \%$ & $\begin{array}{l}0.0579 \\
(10.52)\end{array}$ & $33.10 \%$ & $\begin{array}{c}0.0070 \\
(3.54) \\
\end{array}$ & $\begin{array}{l}0.0576 \\
(8.65)\end{array}$ & $36.88 \%$ & 0.50 \\
\hline \multicolumn{8}{|c|}{ Panel B: Model 2 (the High-Liquidation-Cost Case) } \\
\hline$K Z$ & $R^{2}$ & $W W$ & $R^{2}$ & $K Z$ & $W W$ & $R^{2}$ & $\operatorname{Corr}(K Z, W W)$ \\
\hline $\begin{array}{l}0.0241 \\
(14.57)\end{array}$ & $21.44 \%$ & $\begin{array}{l}0.0748 \\
(13.30)\end{array}$ & $55.41 \%$ & $\begin{array}{l}0.0027 \\
(2.88)\end{array}$ & $\begin{array}{l}0.0735 \\
(11.75)\end{array}$ & $56.52 \%$ & 0.56 \\
\hline \multicolumn{8}{|c|}{ Panel C: Model 2 (the Low-Floatation-Cost Case) } \\
\hline$K Z$ & $R^{2}$ & $W W$ & $R^{2}$ & $K Z$ & $W W$ & $R^{2}$ & $\operatorname{Corr}(K Z, W W)$ \\
\hline $\begin{array}{c}0.0287 \\
(2.16)\end{array}$ & $7.04 \%$ & $\begin{array}{c}0.1413 \\
(7.35)\end{array}$ & $46.01 \%$ & $\begin{array}{c}-0.0161 \\
(-1.13)\end{array}$ & $\begin{array}{c}0.1548 \\
(6.94)\end{array}$ & $49.04 \%$ & 0.47 \\
\hline
\end{tabular}


Figure 1 : The Value and Investment-Policy Functions Against Underlying State Variables, Model 1 with the Dividend Nonnegativity Constraint

This figure plots for Model 1 the market-to-book ratio $\left(v_{j t} / k_{j t}\right.$, Panels A and B) and the investment-to-capital ratio $\left(i_{j t} / k_{j t}\right.$, Panels $\mathrm{C}$ and D) as functions of the state variables. Panels A and C plot the variables as functions of capital stock $k_{j t}$ and firm-specific productivity $z_{j t}$, while fixing the aggregate productivity $x_{t}$ at its long run average level $\bar{x}$. Both Panels $\mathrm{A}$ and $\mathrm{C}$ have a class of curves corresponding to different values of $z_{j t}$, and the arrow in each panel indicates the direction along which $z_{j t}$ increases. Panels B and D plot the variables as functions of capital stock $k_{j t}$ and the aggregate productivity $x_{t}$, while fixing the firm-specific productivity $z_{j t}$ at its long run average level $\bar{z}_{j}=0$. Panels $\mathrm{B}$ and $\mathrm{D}$ have a class of curves corresponding to different values of $x_{t}$, and the arrows indicate the direction along which $x$ increases.

Panel A: $v_{j t}\left(k_{j t}, z_{j t}, \bar{x}\right) / k_{j t}$

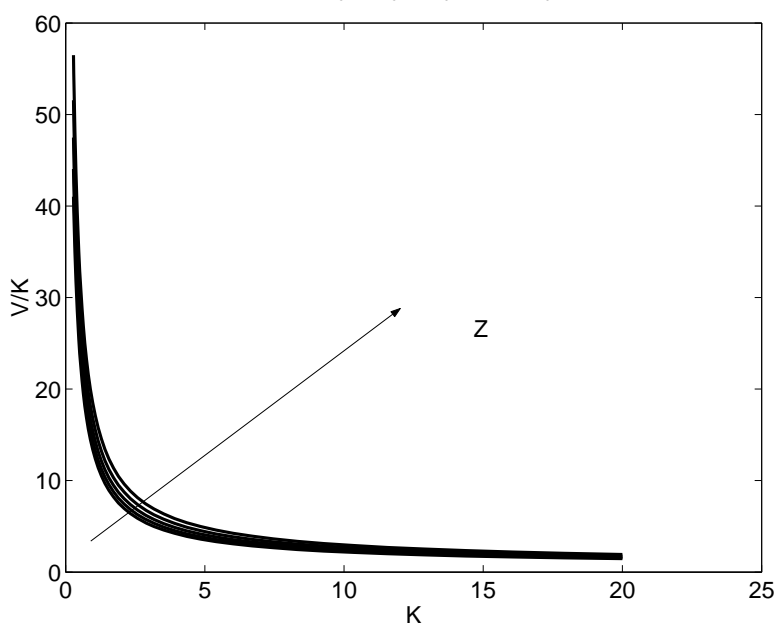

Panel C: $i_{j t}\left(k_{j t}, z_{j t}, \bar{x}\right) / k_{j t}$

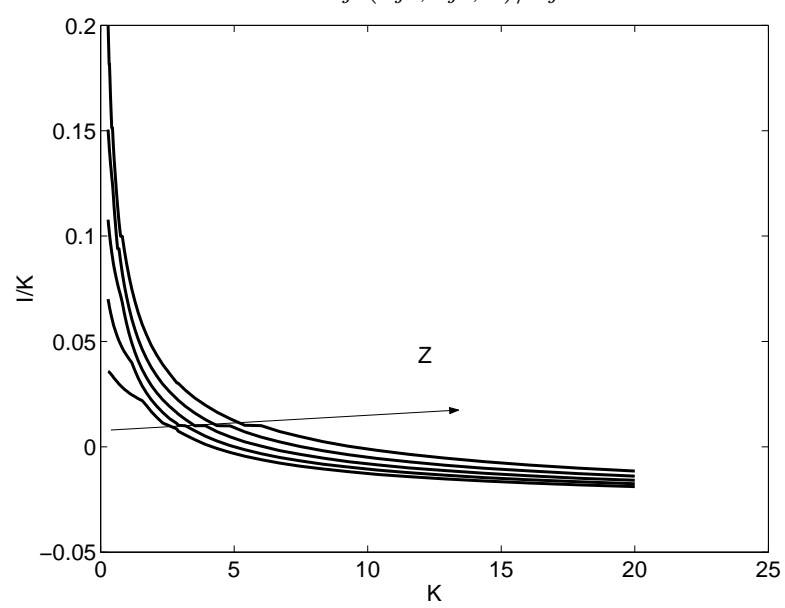

Panel B: $v_{j t}\left(k_{j t}, \bar{z}_{j}, x_{t}\right) / k_{j t}$

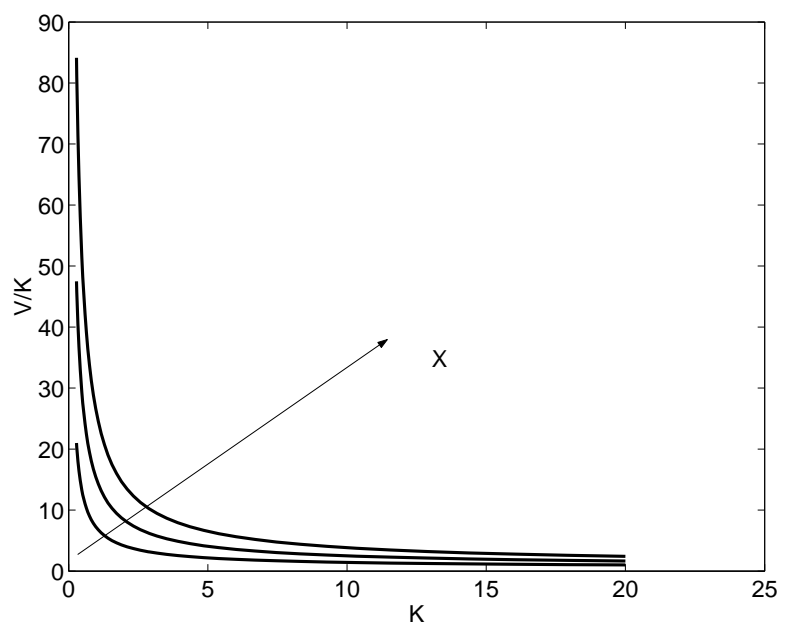

Panel D: $i_{j t}\left(k_{j t}, \bar{z}_{j}, x_{t}\right) / k_{j t}$

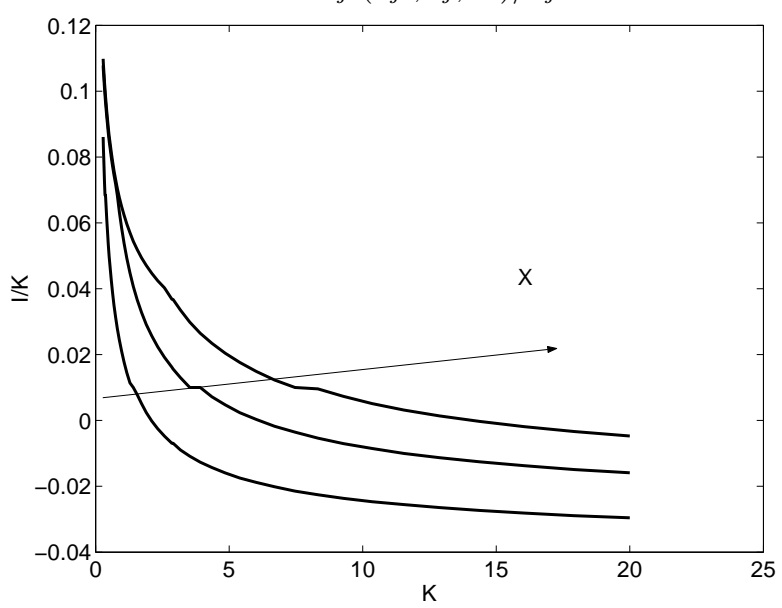


Figure 2 : The Multiplier Against Underlying State Variables: Model 1 with the Dividend Nonnegativity Constraint, the Benchmark Case and the Constant-Discount-Factor Case

For Model 1 under the benchmark parametrization with stochastic discount factor $\left(\gamma_{0}=50, \gamma_{1}=-1000\right)$, Panels $\mathrm{A}$ and $\mathrm{B}$ plot the multiplier, $\mu_{j t}$, against underlying state variables. Panels $\mathrm{C}$ and $\mathrm{D}$ do the same but for Model 1 with constant discount factor $\left(\gamma_{0}=\gamma_{1}=0\right)$. Panels A and $\mathrm{C}$ plot the variables as functions of capital stock $k_{j t}$ and firm-specific productivity $z_{j t}$, while fixing the aggregate productivity $x_{t}$ at its long run average level $\bar{x}$. Both Panels $\mathrm{A}$ and $\mathrm{C}$ have a set of curves corresponding to different values of $z_{j t}$, and the arrow in each panel indicates the direction along which $z_{j t}$ increases. Panels B and D plot the variables as functions of capital stock $k_{j t}$ and the aggregate productivity $x_{t}$, while fixing the firm-specific productivity $z_{j t}$ at its long run average level $\bar{z}_{j}=0$. Panels $\mathrm{B}$ and $\mathrm{D}$ have a class of curves corresponding to different values of $x_{t}$, and the arrows indicate the direction along which $x_{t}$ increases.

Panel A: $\mu_{j t}\left(k_{j t}, z_{j t}, \bar{x}\right)$, Stochastic-Discount-Factor

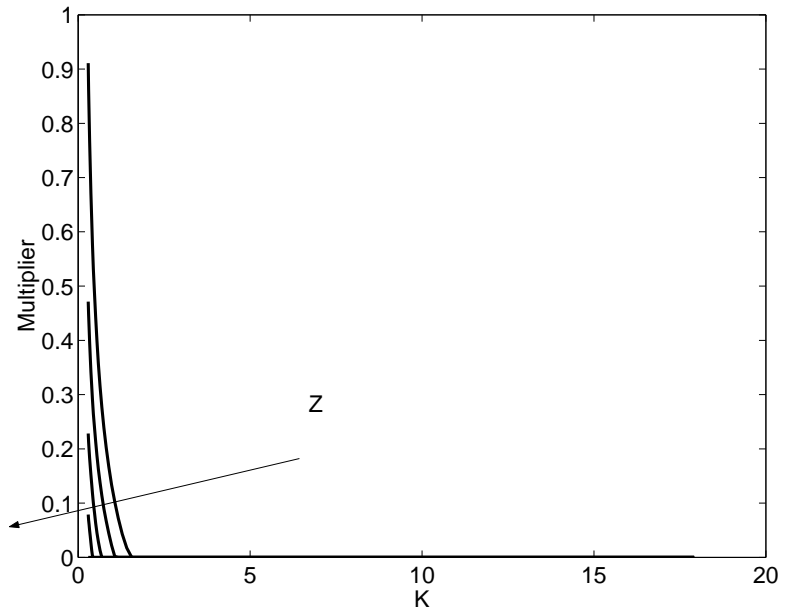

Panel C: $\mu_{j t}\left(k_{j t}, z_{j t}, \bar{x}\right)$, Constant-Discount-Factor

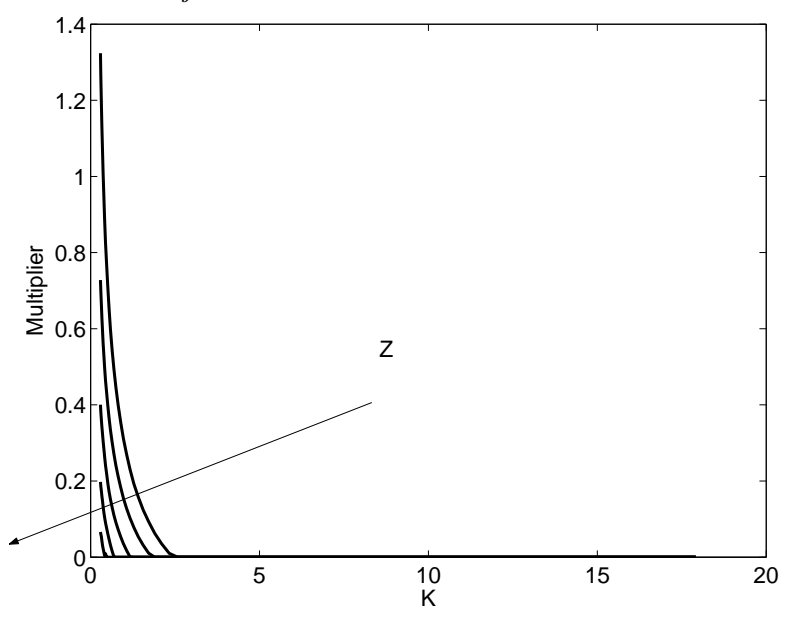

Panel B: $\mu_{j t}\left(k_{j t}, \bar{z}_{j}, x_{t}\right)$, Stochastic-Discount-Factor

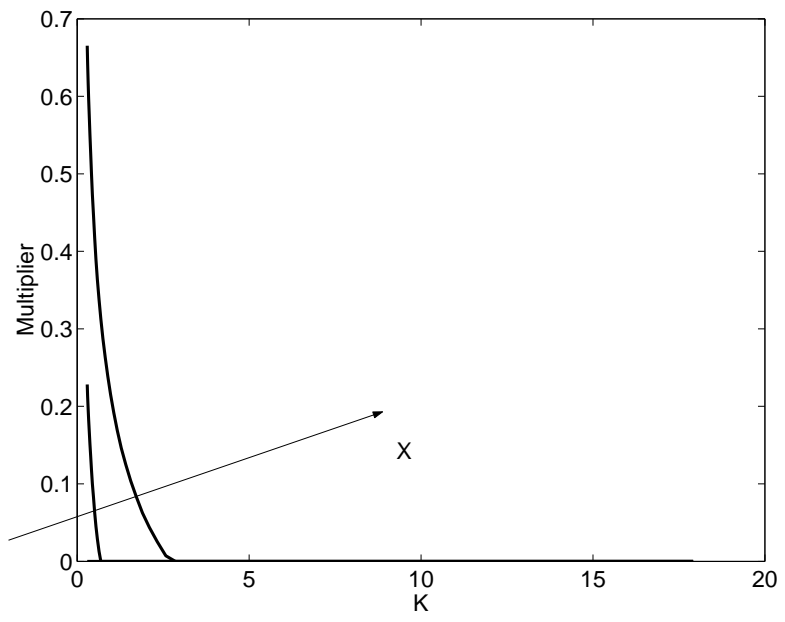

Panel D: $\mu_{j t}\left(k_{j t}, \bar{z}_{j}, x_{t}\right)$, Constant-Discount-Factor

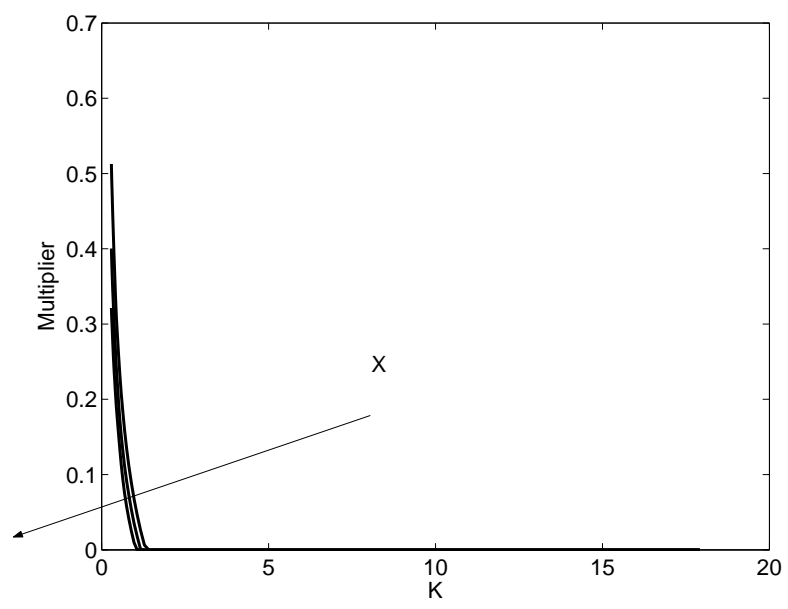


Figure 3 : Risk and Expected Excess Return Against Underlying State Variables: Model 1 with the Dividend Nonnegativity Constraint

This figure plots for Model 1 risk $\left(\beta_{j t}\right.$, Panels A and B) and expected excess return $\left(\mathrm{E}_{t}\left[r_{j t+1}\right]-r_{f t}\right.$, Panels C and D) as functions of the underlying state variables. Panels A and $\mathrm{C}$ plot the variables as functions of capital stock $k_{j t}$ and firm-specific productivity $z_{j t}$, fixing the aggregate productivity $x_{t}$ at its long run average level $\bar{x}$. Panels A and $\mathrm{C}$ report a class of curves corresponding to different values of $z_{j t}$, and the arrow in each panel indicates the direction along which $z_{j t}$ increases. Panels $\mathrm{B}$ and $\mathrm{D}$ plot the variables as functions of capital stock $k_{j t}$ and the aggregate productivity $x_{t}$, fixing the firm-specific productivity $z_{j t}$ at its long run average level $\bar{z}_{j}=0$. Panels B and D report a class of curves corresponding to different values of $x_{t}$, and the arrow in each panel indicates the direction along which $x_{t}$ increases.

Panel A: $\beta_{j t}\left(k_{j t}, z_{j t}, \bar{x}\right)$

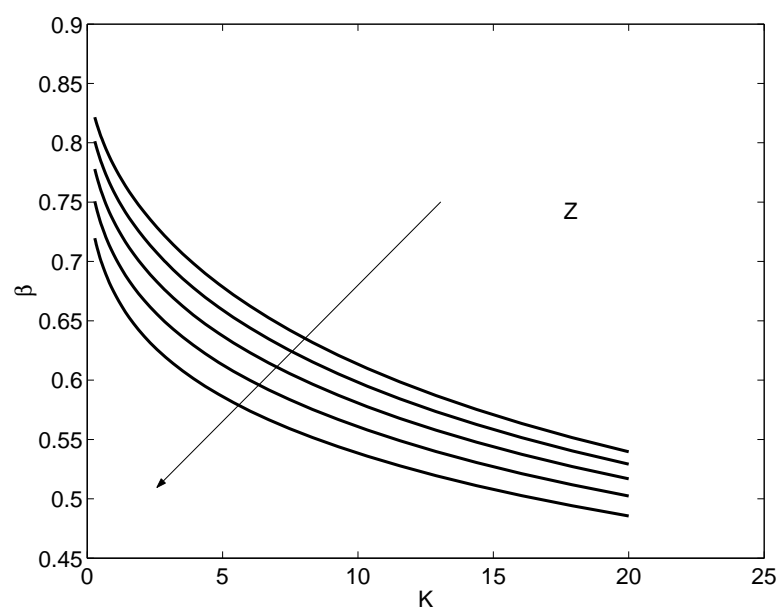

Panel C: $\mathrm{E}_{t}\left[r_{j t+1}-r_{f t}\right]\left(k_{j t}, z_{j t}, \bar{x}\right)$

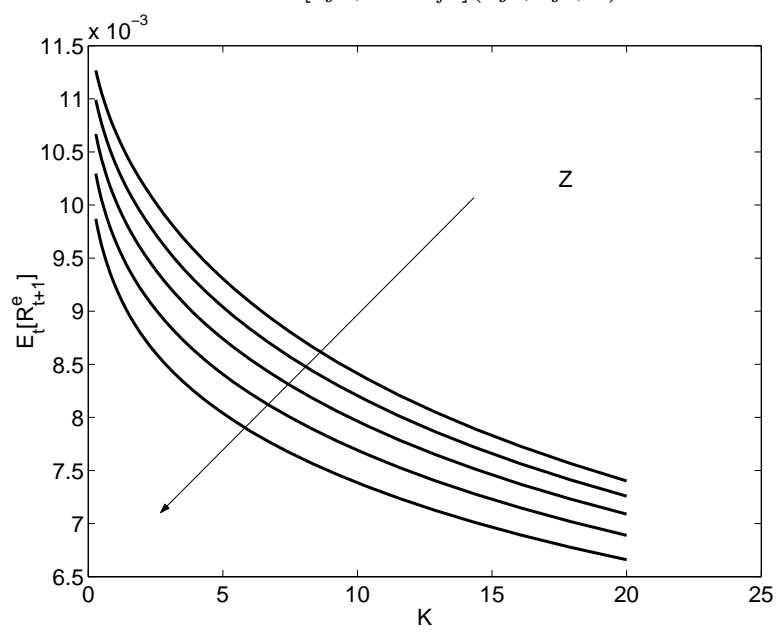

Panel B: $\beta_{j t}\left(k_{j t}, \bar{z}_{j}, x_{t}\right)$

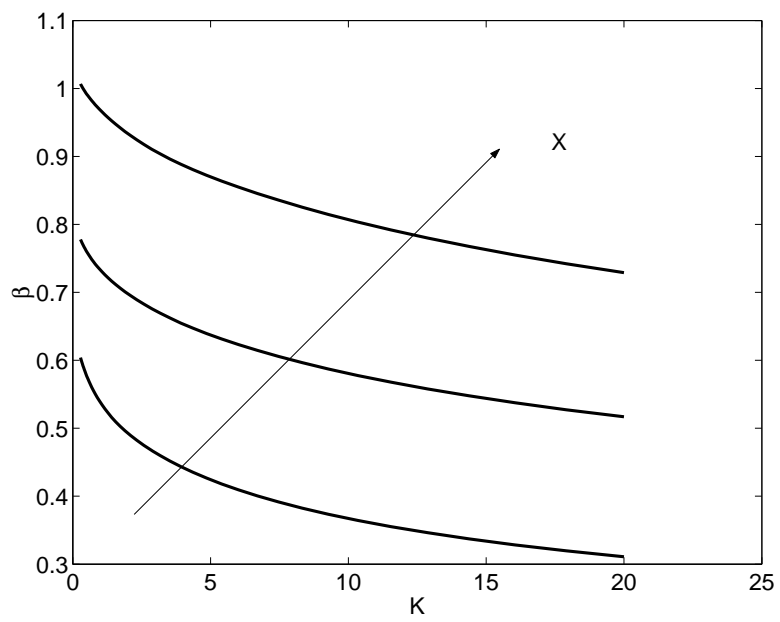

Panel D: $\mathrm{E}_{t}\left[r_{j t+1}-r_{f t}\right]\left(k_{j t}, \bar{z}_{j}, x_{t}\right)$

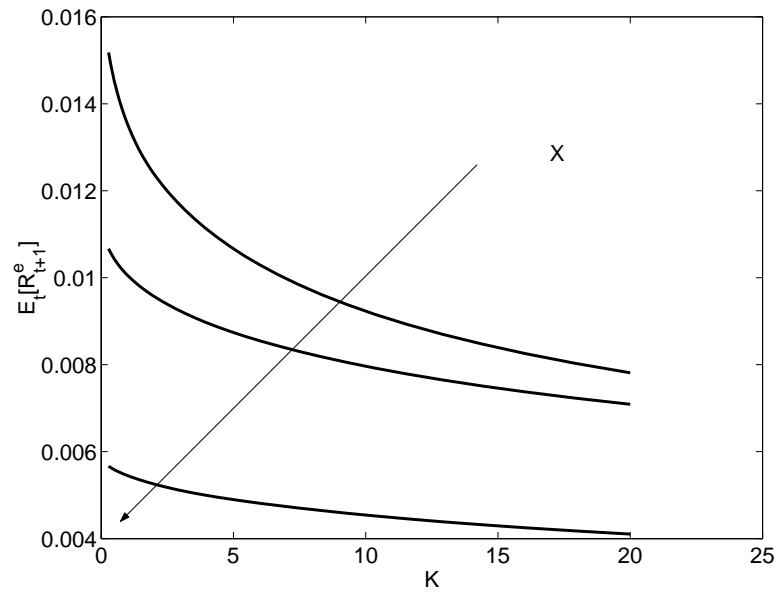




\section{Figure 4: The Value and Investment-Policy Functions Against Underlying State Variables, Model 2 with the Collateral Constraint}

This figure plots for Model 2 the ratio of market value of equity to capital $\left(v_{j t} / k_{j t}\right.$, Panels A and B) and the optimal investment-to-capital ratio $\left(i_{j t} / k_{j t}\right.$, Panels $\mathrm{C}$ and $\left.\mathrm{D}\right)$ as functions of underlying state variables. Panels $\mathrm{A}$ and $\mathrm{C}$ plot the variables as functions of current-period debt, $b_{j t}$, and firm-specific productivity, $z_{j t}$, while fixing the aggregate productivity $x_{t}$ and capital stock $k_{j t}$ at their respective long run average levels, $\bar{x}$ and $\bar{k}$ ( $\bar{k}$ is determined in model simulations). Panels $\mathrm{A}$ and $\mathrm{C}$ have a class of curves, corresponding to different values of $z_{j t}$, and the arrow in each panel indicates the direction along which $z_{j t}$ increases. Panels B and D plot the variables as functions of currentperiod debt, $b_{j t}$, and the aggregate productivity $x_{t}$, fixing the firm-specific productivity $z_{j t}$ and capital stock $k_{j t}$ at their long run average levels. Panels B and D have a class of curves corresponding to different values of $x_{t}$, and the arrows indicate the direction along which $x_{t}$ increases.
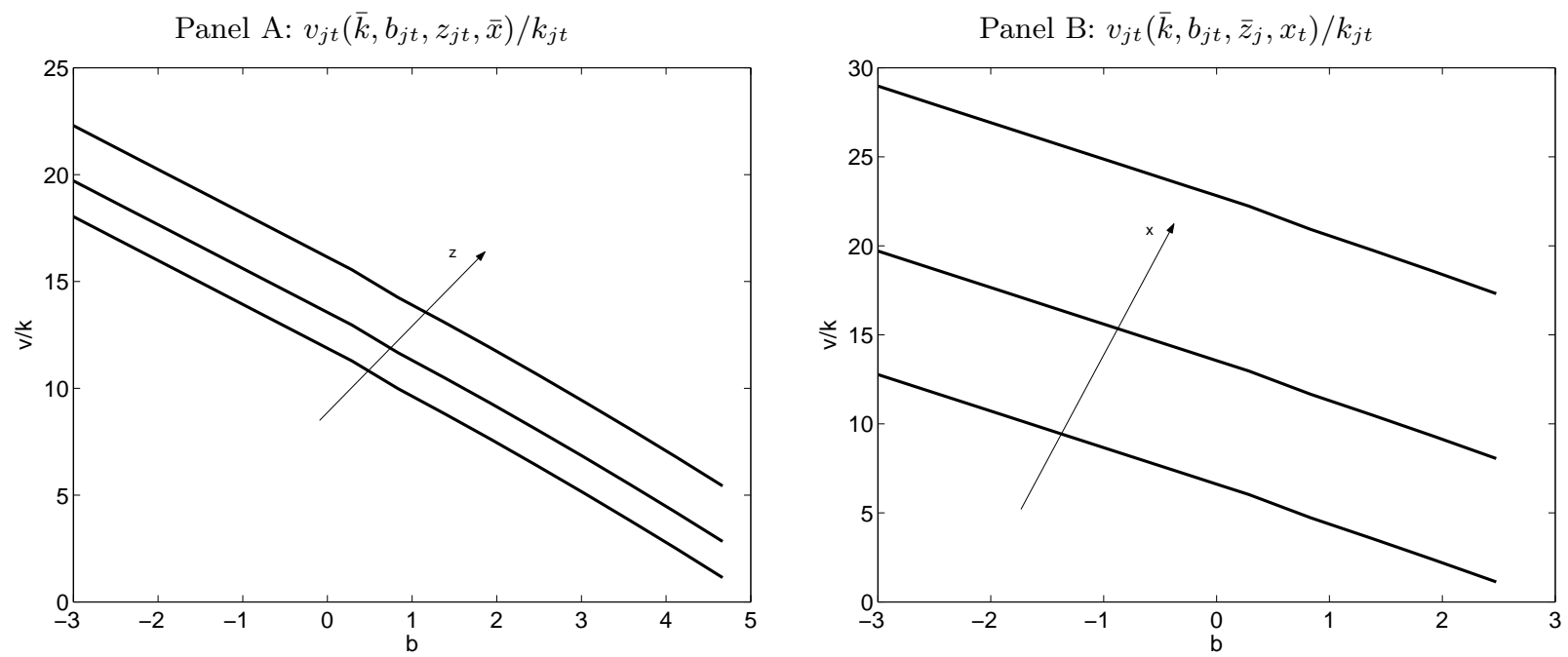

Panel C: $i_{j t}\left(\bar{k}, b_{j t}, z_{j t}, \bar{x}\right) / k_{j t}$

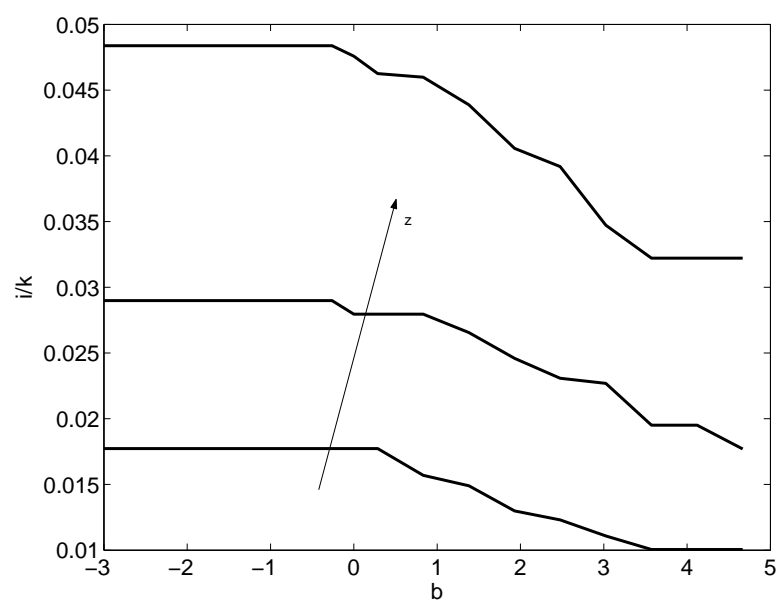

Panel D: $i_{j t}\left(\bar{k}, b_{j t}, \bar{z}_{j}, x_{t}\right) / k_{j t}$

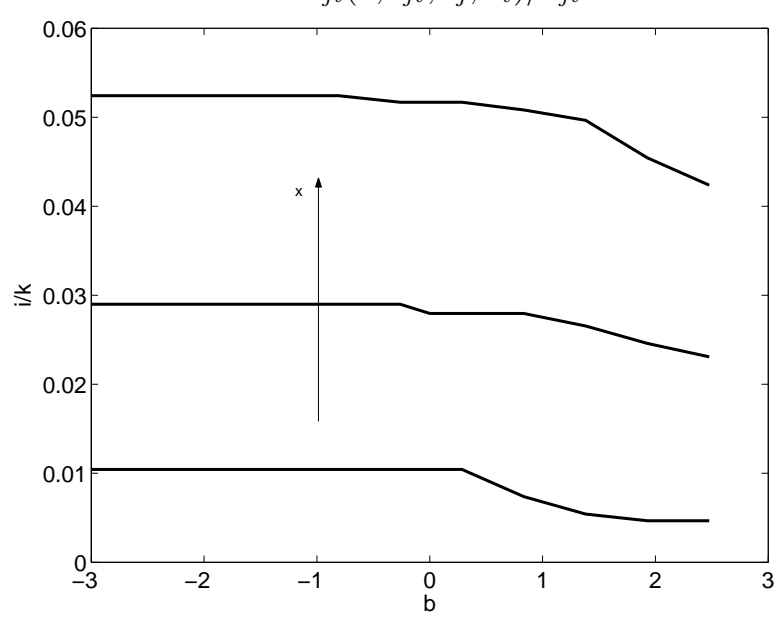




\section{Figure 5 : The Optimal Debt-Policy Function Against Underlying State Variables, Model 2 with the Collateral Constraint}

This figure plots for Model 2 the optimal next-period-debt-to-capital ratio, $b_{j t+1} / k_{j t}$, as functions of underlying state variables. Panel A plots the debt-policy function against capital stock $k_{j t}$ and firm-specific productivity $z_{j t}$, while fixing aggregate productivity $x_{t}$ and current-period debt $b_{j t}$ at their respective long run average levels, $\bar{x}$ and $\bar{b}(\bar{b}$ is determined in model simulations). Panel B plots the optimal debt-policy function against capital stock $k_{j t}$ and aggregate productivity $x_{t}$, while fixing $z_{j t}$ and $b_{j t}$ at their respective long run average levels, $\bar{z}_{j}=0$ and $\bar{b}$. Panel $\mathrm{C}$ plots the debt-policy function against current-period debt $b_{j t}$ and firm-specific productivity $z_{j t}$, while fixing aggregate productivity $x_{t}$ and capital stock $k_{j t}$ at their respective long run average levels, $\bar{x}$ and $\bar{k}$ ( $\bar{k}$ is determined in model simulations). Finally, Panel D plots the debt-policy function against $b_{j t}$ and $x_{t}$, while fixing $z_{j t}$ and $k_{j t}$ at their respective long run average levels. Panels $\mathrm{A}$ and $\mathrm{C}$ have a class of curves, corresponding to different values of $z_{j t}$, and the arrow in each panel indicates the direction along which $z_{j t}$ increases. Panels $\mathrm{B}$ and D have a class of curves corresponding to different values of $x_{t}$, and the arrows indicate the direction along which $x_{t}$ increases.

Panel A: $b_{j t+1}\left(k_{j t}, \bar{b}, z_{j t}, \bar{x}\right) / k_{j t}$

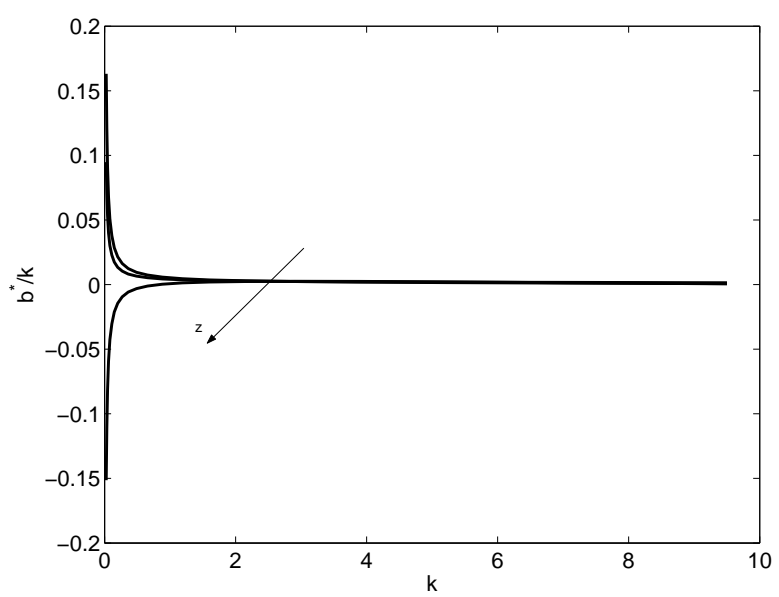

Panel C: $b_{j t+1}\left(\bar{k}, b_{j t}, z_{j t}, \bar{x}\right) / k_{j t}$

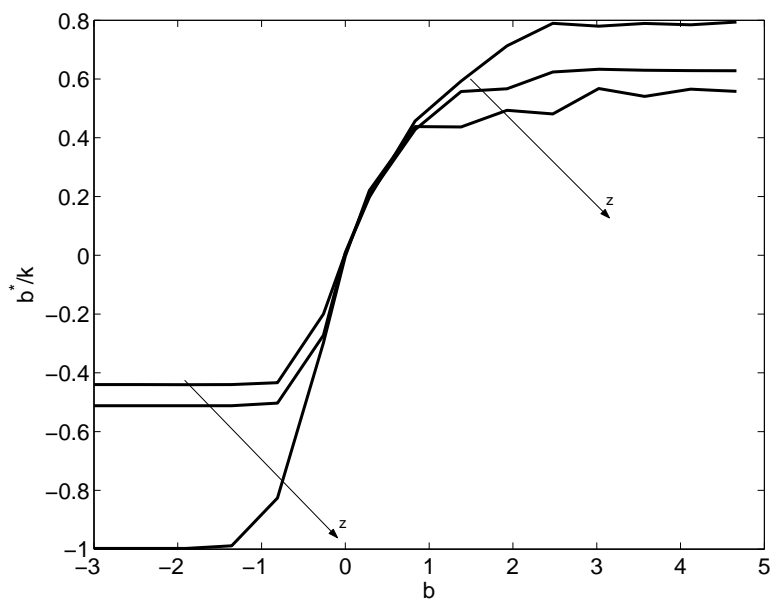

Panel B: $b_{j t+1}\left(k_{j t}, \bar{b}, \bar{z}_{j}, x_{t}\right) / k_{j t}$

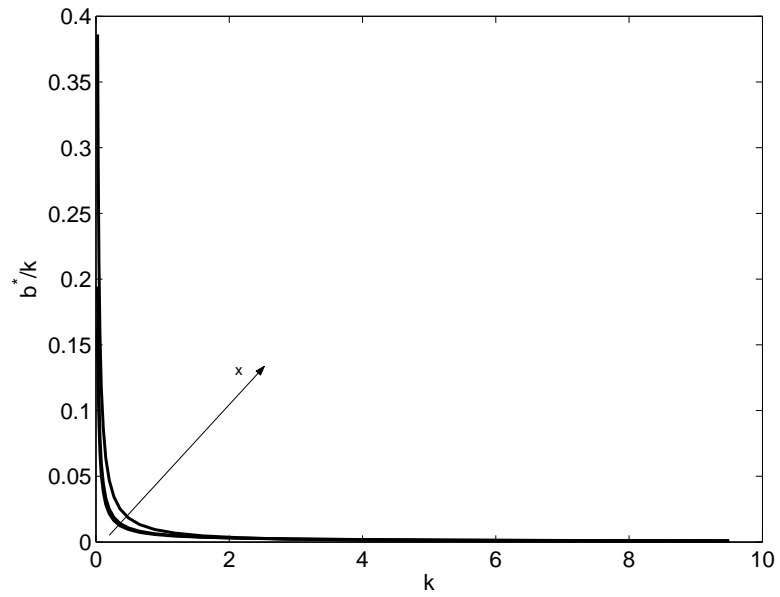

Panel D: $b_{j t+1}\left(\bar{k}, b_{j t}, \bar{z}_{j}, x_{t}\right) / k_{j t}$

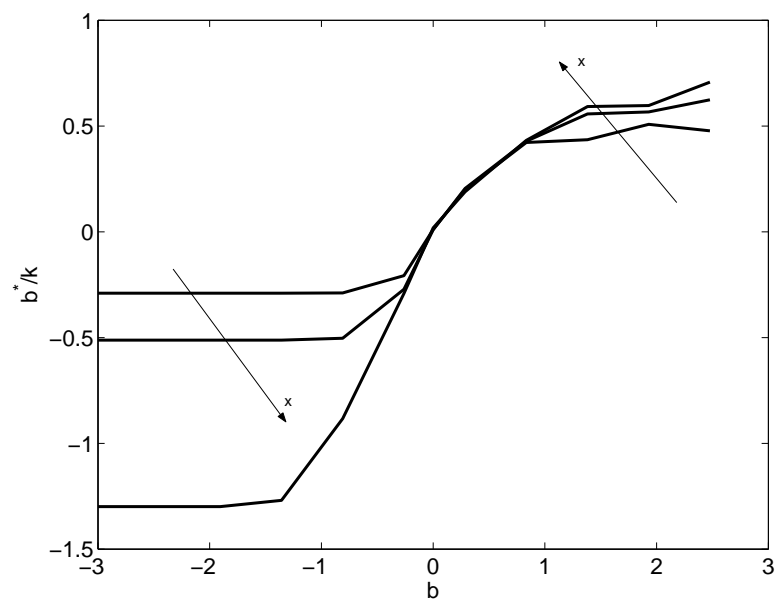


Figure 6 : The Multiplier Against Underlying State Variables, Model 2 with the Collateral Constraint

This figure plots for Model 2 the multiplier, $\nu_{j t}$, associated with the collateral constraints as functions of underlying state variables. Panel A plots the multiplier against capital stock $k_{j t}$ and firm-specific productivity $z_{j t}$, while fixing aggregate productivity $x_{t}$ and current-period debt $b_{j t}$ at their respective long run average levels, $\bar{x}$ and $\bar{b}(\bar{b}$ is determined in model simulations). Panel B plots the multiplier against capital stock $k_{j t}$ and aggregate productivity $x_{t}$, while fixing $z_{j t}$ and $b_{j t}$ at their respective long run average levels, $\bar{z}_{j}=0$ and $\bar{b}$. Panel $\mathrm{C}$ plots the multiplier against current-period debt $b_{j t}$ and firm-specific productivity $z_{j t}$, while fixing aggregate productivity $x_{t}$ and capital stock $k_{j t}$ at their respective long run average levels, $\bar{x}$ and $\bar{k}(\bar{k}$ is determined in model simulations). And Panel D plots the multiplier against $b_{j t}$ and $x_{t}$, while fixing $z_{j t}$ and $k_{j t}$ at their respective long run average levels. Panels $\mathrm{A}$ and $\mathrm{C}$ have a class of curves, corresponding to different values of $z_{j t}$, and the arrow in each panel indicates the direction along which $z_{j t}$ increases. Panels $\mathrm{B}$ and $\mathrm{D}$ have a class of curves corresponding to different values of $x_{t}$, and the arrows indicate the direction along which $x_{t}$ increases.
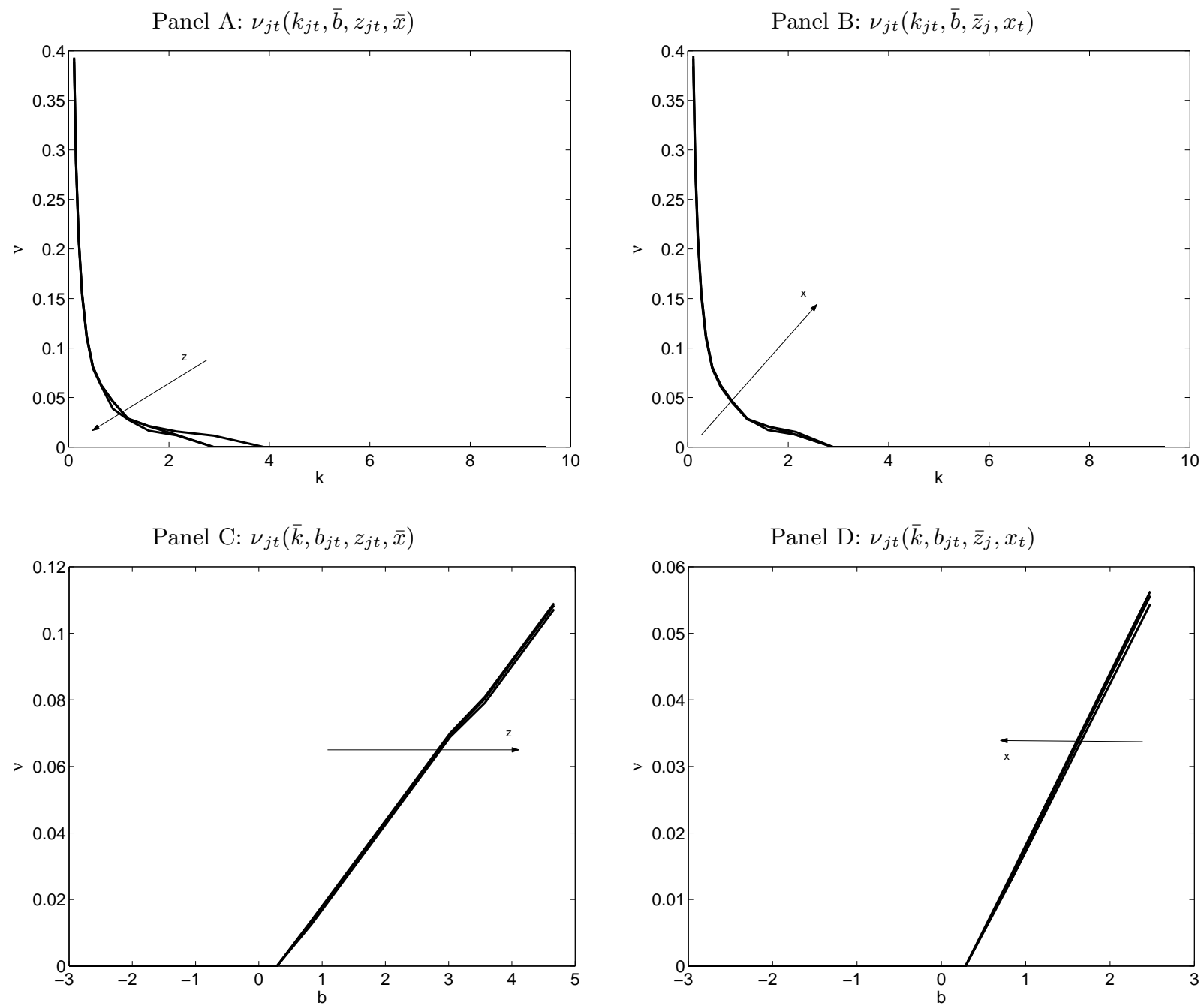


\section{Figure 7 : Risk and Expected Excess Return Against Underlying State Variables, Model 2 with the Collateral Constraint}

This figure plots for Model 2 risk, $\beta_{j t}$, in Panels A and B, and expected excess return, $\mathrm{E}_{t}\left[r_{j t+1}\right]-r_{f t}$ in Panels C and $\mathrm{D}$ against underlying state variables. Panels $\mathrm{A}$ and $\mathrm{C}$ plot the variables against current debt, $b_{j t}$, and firm-specific productivity, $z_{j t}$, while fixing aggregate productivity, $x_{t}$, and capital stock, $k_{j t}$, at their respective long run average levels, $\bar{x}$ and $\bar{k}$ ( $\bar{k}$ is determined in model simulations). In Panels $\mathrm{A}$ and $\mathrm{C}$, we plot a class of curves, corresponding to different values of $z_{j t}$, and the arrow in each panel indicates the direction along which $z_{j t}$ increases. Panels $\mathrm{B}$ and D plot the variables against current debt, $b_{j t}$, and aggregate productivity, $x_{t}$, while fixing firm-specific productivity, $z_{j t}$, and capital stock, $k_{j t}$, at their respective long run average levels, $\bar{z}_{j}=0$ and $\bar{k}$. In Panels $\mathrm{B}$ and $\mathrm{D}$, we report a class of curves corresponding to different values of $x_{t}$, and the arrows indicate the direction along which $x_{t}$ increases.

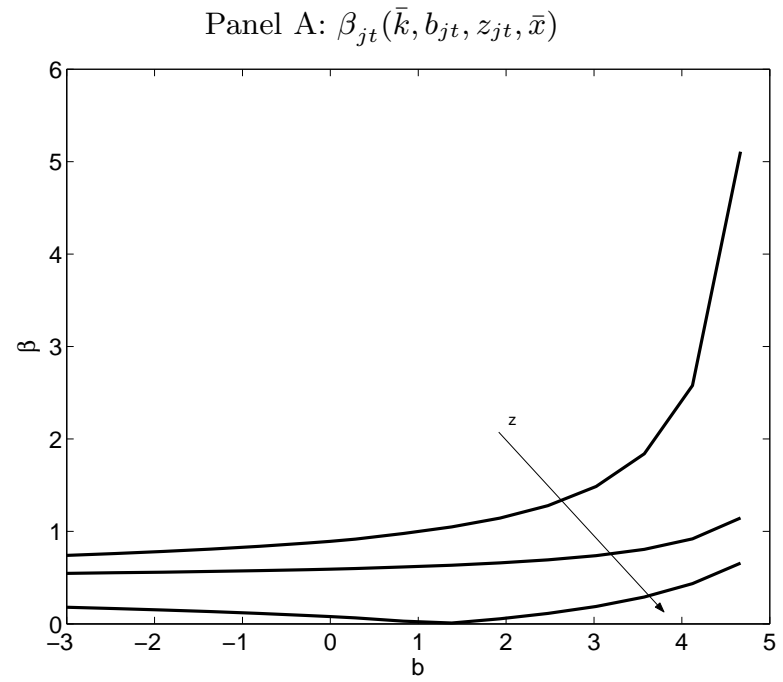

Panel C: $\mathrm{E}_{t}\left[r_{j t+1}-r_{f t}\right]\left(\bar{k}, b_{j t}, z_{j t}, \bar{x}\right)$

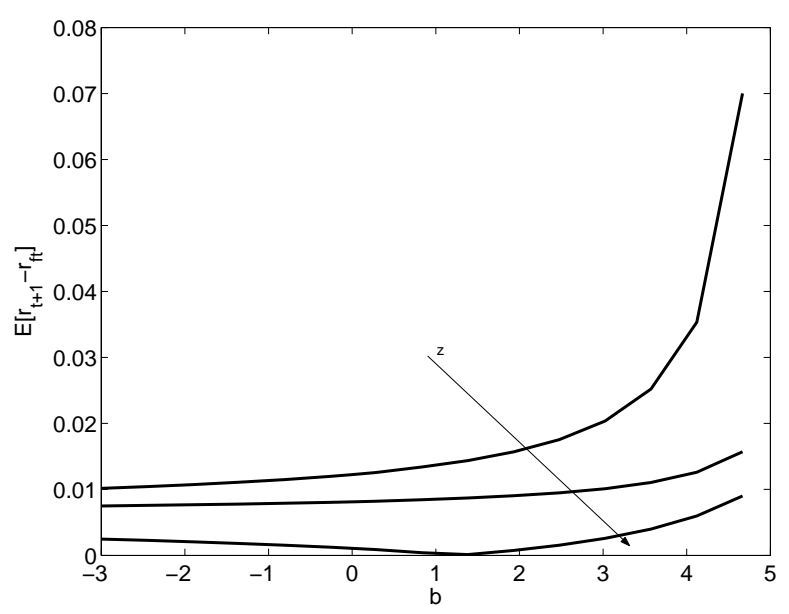

Panel B: $\beta_{j t}\left(\bar{k}, b_{j t}, \bar{z}_{j}, x_{t}\right)$

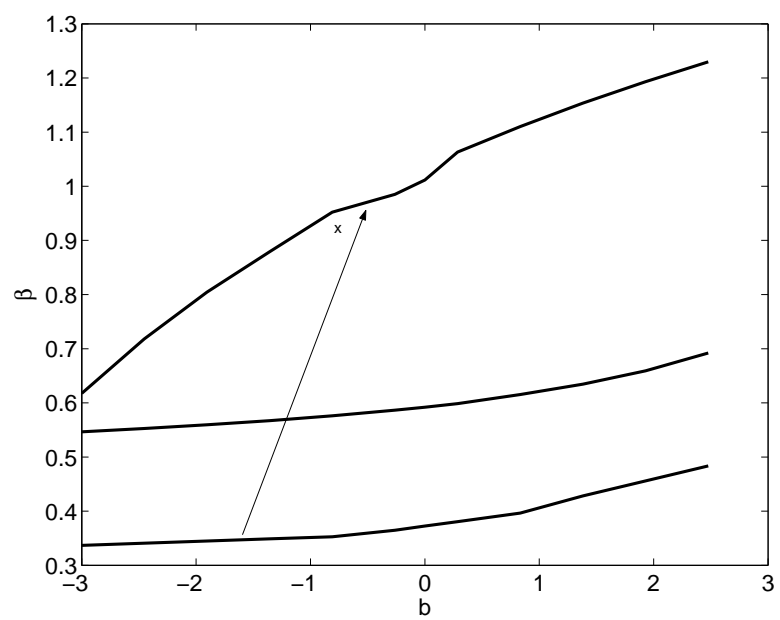

Panel D: $\mathrm{E}_{t}\left[r_{j t+1}-r_{f t}\right]\left(\bar{k}, b_{j t}, \bar{z}_{j}, x_{t}\right)$

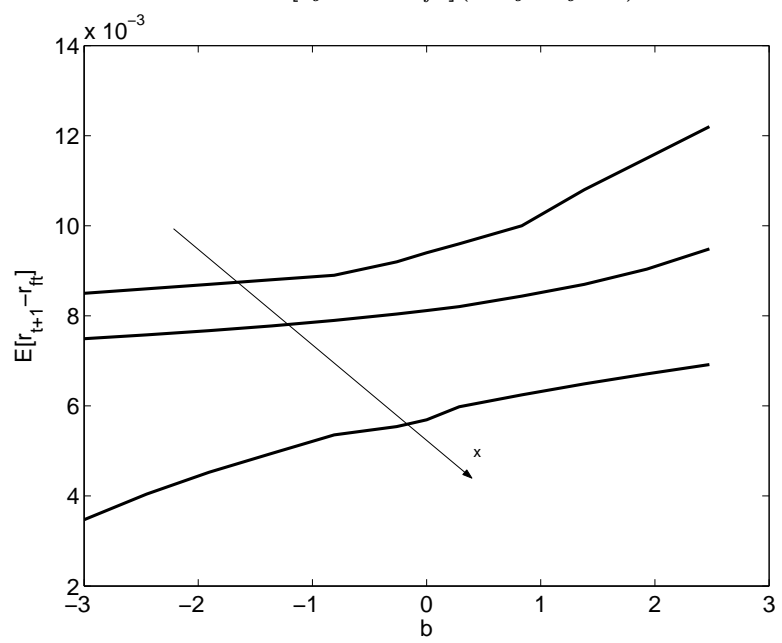

